\title{
¿ES CONSTITUCIONAL LA DIVISIÓN de la Corte Suprema en salas?
}

\section{Manuel José García-Mansilla*}

\author{
Facultad de Derecho, Universidad Austral \\ MGarciaMansilla@austral.edu.ar
}

Recibido: $6 / 10 / 2020$

Aceptado: 3/11/2020

\section{Resumen}

Este trabajo examina desde una perspectiva histórica varias propuestas diferentes para dividir a la Corte Suprema argentina en salas y analiza los problemas constitucionales de este tipo de iniciativas de reforma.

Palabras clave: Corte Suprema, división en salas, Constitución Nacional.

\section{Is the Division of the Supreme Court in Panels Constitutional?}

\begin{abstract}
This article examines from a historical perspective several different proposals to divide the Argentine Supreme Court in panels and analyzes the constitutional problems of these kind of reform initiatives.
\end{abstract}

Key words: Supreme Court, division in panels, Constitution of Argentina.

\section{Introducción}

El Consejo Consultivo para el Fortalecimiento del Poder Judicial y del Ministerio Público, creado en el ámbito de la Presidencia de la Nación a través del Decreto $635 / 2020,{ }^{1}$ tiene como objetivo principal estudiar y proponer reformas

Agradezco a Alfonso Santiago (h), Antonio María Hernández, Carlos Laplacette, José Sebastián Elías, Jerónimo Lau Alberdi, Iván Vigani, Santiago Castro Videla, Pedro Caminos, Santiago Gascón, Gregorio Uriburu y Ricardo Ramírez Calvo, quienes me hicieron valiosos comentarios, críticas 
acerca de diversos temas, incluida la Corte Suprema de Justicia de la Nación. La creación de este Consejo Consultivo puso nuevamente en discusión la vieja idea de dividir a la Corte Suprema en salas. ${ }^{2}$ Así, en los últimos meses, algunas voces se manifestaron públicamente a favor de esa división, con propuestas de diversa índole. Ese tipo de iniciativas van desde la del exjuez Eugenio Zaffaroni de elevar la Corte a quince jueces y dividirla en cinco salas especializadas, ${ }^{3}$ la del exjuez Carlos Rozanski, expuesta en el plenario de Comisiones en el Senado de la Nación, de llevarla a veintiún jueces para dividirla en salas, incluyendo una sala de niñez y adolescencia (una supuesta "deuda de la democracia argentina" $)^{4}$ y hasta la de elevarla a una cantidad indeterminada de jueces para luego dividirla en salas especializadas que tampoco se especifican, propuesta públicamente en un reportaje por el exjuez Eduardo Freiler. ${ }^{5}$

Una lectura rápida del Decreto 635/2020 indicaría que el Consejo Consultivo no tiene a su cargo elaborar propuestas y recomendaciones para modificar la organización interna de la Corte Suprema. Por ende, sería superfluo analizar la posibilidad de una eventual propuesta de modificación a través de su división en salas. Sin embargo, la redacción del decreto en cuestión es ambigua en este punto. El artículo 7, inciso 1) prevé la elaboración de un informe acerca de proyectos de ley presentados durante los últimos 10 años "tendientes a establecer modificaciones en la composición, organización y funcionamiento de la CORTE SUPREMA DE JUSTICIA DE LA NACIÓN”. La revisión de

y sugerencias que enriquecieron este trabajo. Todas las opiniones vertidas en este trabajo son a título estrictamente personal.

1 BO 30/07/2020, https://www.boletinoficial.gob.ar/detalleAviso/primera/232757/20200730.

2 A modo de ejemplo, León Arslanian, uno de los integrantes del Consejo Consultivo, propuso en 2014 aumentar el número de jueces de la Corte a 9 y dividirla en salas: "A mí me parece que la Corte, primero, si quiere ganar en eficacia, tiene que achicar la circulación y trabajar por salas: una sala penal, una de derecho público, una civil y comercial” (Sehinkman, 2014).

3 Ver Zaffaroni propone una Corte Suprema... (2020).

4 Ver Barcesat, sobre la reforma judicial... (2020).

5 Ver Eduardo Freiler: Extender la Corte... (2020). En ese reportaje, el exjuez Freiler, removido por el Consejo de la Magistratura, afirmó: "Creo que es necesario ampliar el número de la Corte, pero no solamente por la idea de quienes están hoy integrando el más alto tribunal sino, que realmente es impensable para una estructura que cinco personas pretendan conocer de absolutamente todo, y ser especialistas en tener la última palabra sobre diferentes ramas del derecho. En este momento, no tenemos ningún penalista, no hay ningún laboralista, no tenemos una persona especialista en derecho familiar con una visión de género, y además, creo que es una Corte que estructuralmente atrasa muchísimo. Hay que extender a un gran número de jueces divididos por salas donde se especialicen por temas, salas penales, por ejemplo, y demás, sería también posible que los presidentes de cada una de estas salas se reúnan, y conformen un tipo de tribunal constitucional". 
algunos de esos proyectos de ley presentados en el Congreso de la Nación de 2010 a la fecha demuestra que introducir modificaciones a la composición y organización y funcionamiento de la Corte Suprema fue una inquietud recurrente de algunos legisladores nacionales. Esos proyectos de ley incluyen no solo el eventual aumento de la cantidad de sus miembros, sino también su división en salas. ${ }^{6}$ Además, el artículo 4 , in fine, establece que "Para realizar su cometido el Consejo Consultivo evaluará las iniciativas legislativas ingresadas al HONORABLE CONGRESO DE LA NACIÓN en los últimos DIEZ (10) años vinculadas con los temas sometidos a su análisis".

¿Están vinculados este tipo de proyectos de ley que incluyen iniciativas de modificación de la organización de la Corte Suprema con los temas sometidos al análisis del Consejo Consultivo? Parecería que sí. Además, dada la amplitud con la que están redactados los incisos 1 y 2 del artículo 4 del Decreto 635/2020 es imposible descartarlo. En efecto, el Consejo Consultivo está obligado a elaborar un dictamen de propuestas y recomendaciones basadas en: (i) una "Descripción valorativa con especial indicación de los problemas que se observan para el correcto funcionamiento de la CORTE SUPREMA DE JUSTICIA DE LA NACIÓN [...]”; y (ii) un análisis del funcionamiento de la Corte "que incluya: a) El establecimiento para la selección de integrantes, de criterios de diversidad de género y representación federal [...]”. ${ }^{7}$ En consecuencia, el

6 Ver, por ejemplo, el proyecto presentado por los senadores Marcelo Fuentes, Virginia M. García, Silvina García Larraburu, Juan Irrazábal, María Labado, Mirtha M. T. Luna, Anabel Fernández Sagasti, María Pilatti Vergara, Inés I. Blas, Ruperto Godoy, Ana C. Almirón, Hilda C. Aguirre de Soria, María de los Ángeles Sacnun y Nancy González en 2016, cuyo artículo segundo establece: "INCORPÓRASE como Artículo 21 del Decreto Ley No 1285/58, texto según Ley No 16.895, el cual quedará redactado de la siguiente forma: -Artículo 21.- La Corte Suprema de Justicia de la Nación estará compuesta por TRECE (13) jueces y funcionará dividida en CUATRO (4) Salas que distribuirán sus funciones en razón de la materia, integradas por TRES (3) miembros cada una, ejerciendo la presidencia del tribunal el juez restante. La presidencia será ejercida por un periodo de DOS (2) años, es reelegible y su designación resulta del voto mayoritario de los miembros del Máximo tribunal. Ante la Corte Suprema de Justicia actuarán el Procurador General de la Nación y los Procuradores Fiscales ante la Corte Suprema de Justicia de la Nación y el Defensor General de la Nación y los Defensores Oficiales ante la Corte Suprema de Justicia de la Nación en los términos de la ley 24.946 y demás legislación complementaria" (ver https://www.senado.gob.ar/parlamentario/ comisiones/verExp/1967.16/S/PL).

7 En sentido similar, los senadores Norma Durango, Juan Manuel Abal Medina, Marina Riofrio, Sigrid Kunath, María Graciela de la Rosa y Beatriz G. Mirkin de Alperovich presentaron en 2016 un proyecto cuyo artículo 1 establece: "[...] La Corte Suprema de Justicia de la Nación estará compuesta por siete (7) jueces. Ante ella actuarán el Procurador General de la Nación y los Procuradores Fiscales ante la Corte Suprema de Justicia de la Nación y el Defensor General de la Nación y los Defensores Oficiales ante la Corte Suprema de Justicia de la Nación en los términos de las leyes 24.946, 27.148 y 27.149 y demás legislación complementaria. La composición de la Corte Suprema de Justicia de la Nación deberá 
Consejo Consultivo no tiene impedimento alguno para incluir en su dictamen una propuesta de división de la Corte Suprema en salas.

En ese marco, parece necesario analizar la cuestión desde la perspectiva constitucional y verificar si la Constitución permite o no una modificación de esta naturaleza. A fin de poner en contexto este tipo de propuestas, haré primero un breve repaso histórico de las principales iniciativas de dividir a la Corte en salas. Luego, revisaré la opinión de diversos autores nacionales al respecto, para después analizar la compatibilidad de esa división o no con nuestro sistema constitucional y hacer una evaluación crítica acerca de si, en cualquier caso, existe algún beneficio derivado de esa modificación en la organización interna de la Corte Suprema. Finalmente, daré mis conclusiones.

\section{Antecedentes históricos}

La idea de dividir a la Corte Suprema en salas dista de ser novedosa. De hecho, se ha planteado en numerosas ocasiones y de forma infructuosa en nuestro país desde por lo menos 1826 a la fecha. A continuación, citaré todos los antecedentes que he encontrado y que considero más relevantes sobre este tema, con la exposición de los fundamentos que se esgrimieron en cada caso. Más allá de que casi todos esos intentos fueron infructuosos, su revisión permite vislumbrar los diversos argumentos que se presentaron para poder analizarlos después desde la perspectiva constitucional.

\subsection{Antecedentes anteriores a la sanción de la Constitución de $\mathbf{1 8 5 3}$}

La Constitución de Cádiz de 1812 no fue un antecedente relevante de la Constitución Nacional. Sin embargo, influyó en el primer antecedente nacional que propuso una corte dividida en salas. Por eso, vale la pena hacer una breve referencia a su organización judicial, a la que algunos autores le atribuyen erróneamente influencia en nuestro sistema constitucional. ${ }^{8}$

El artículo 259 de la constitución gaditana establecía un Supremo Tribunal

reflejar en su integración las diversidades de género y procedencia regional en el marco del ideal de representación de un país federal. A efectos de asegurar la diversidad de género, la Corte Suprema de Justicia de la Nación no podrá integrarse por más de cuatro (4) jueces del mismo género" (ver https:// www.senado.gob.ar/parlamentario/comisiones/verExp/2039.16/S/PL).

8 Para un análisis detallado de ese aspecto, ver García-Mansilla y Ramírez Calvo (2006, pp. 107 y ss.). 
de Justicia. ${ }^{9}$ Y, conforme lo previsto en el artículo 260, el Poder Legislativo determinaría "el número de magistrados que han de componerle, y las salas en que ha de distribuirse" el Supremo Tribunal. ${ }^{10}$ Entre sus múltiples competencias, correspondía al Supremo Tribunal español el conocimiento de los recursos de nulidad contra las sentencias finales de las Audiencias "para el preciso efecto de reponer el proceso, devolviéndolo, y obtener así la efectividad de la responsabilidad judicial por la infracción de las leyes que arreglan el proceso en lo civil". Además, intervendría en las cuestiones de competencia, ${ }^{11}$ en los delitos cometidos por los altos cargos políticos y los magistrados del propio Supremo Tribunal, ${ }^{12}$ en los juicios políticos contra secretarios de Estado y del despacho, consejeros de Estado y magistrados judiciales, ${ }^{13}$ en los juicios de residencia, ${ }^{14}$ en los asuntos contenciosos del patronato rea ${ }^{15} \mathrm{y}$ en los recursos contra decisiones de los tribunales eclesiásticos. ${ }^{16}$

Es importante destacar que la Constitución de Cádiz prohibía a los tribunales suspender la ejecución de las leyes, es decir, controlar su constitucionalidad. ${ }^{17}$ Esta prohibición era copia de lo dispuesto en el artículo 10, título I de la ley francesa del 16-24 de agosto de 1790, replicado luego en el capítulo $\mathrm{V}$, artículo $3^{\circ}$ de la Constitución francesa de 1791. Así es que la Constitución española de 1812 incluye entre las atribuciones del Supremo Tribunal la de "[o] ír las dudas de los demás tribunales sobre la inteligencia de alguna ley, y consultar sobre ellas al Rey con los fundamentos que hubiere, para que promueva la conveniente declaración de las Cortes" ${ }^{18}$ Esta atribución es copia de lo dispuesto en el artículo 12, título I de la referida ley francesa de agosto de 1790: "Los jueces [...] dirigirán representaciones al cuerpo legislativo cuando estimen necesario interpretar el sentido dudoso de una ley o dotarse de una nueva". ${ }^{19}$

9 El texto completo junto con el Discurso Preliminar pueden encontrarse en Sevilla Andrés (1969, pp. 115 y ss.). El artículo citado se encuentra en la p. 199.

10 Ídem.

11 Artículo 261, Primero.

12 Artículo 261, Cuarto y Quinto.

13 Artículo 261, Segundo y Tercero.

14 Artículo 261, Sexto.

15 Artículo 261, Séptimo.

16 Artículo 261, Octavo.

17 Artículo 246.

18 Artículo 261, Décimo. "Cortes" es el nombre del Poder Legislativo en la Constitución de Cádiz.

19 Una descripción detallada de esa organización puede encontrarse en Collantes de Terán de la Hera (2006, pp. 97-108). 
Estas disposiciones muestran las enormes diferencias existentes entre la organización de los tribunales en la Constitución de Cádiz y la del Poder Judicial a partir de la sanción de la Constitución Nacional en 1853. Sin embargo, el primer antecedente patrio de división de la Corte Suprema en salas muestra la influencia de la Constitución gaditana en este punto. Me refiero a la Constitución de 1826 que, luego de establecer una Alta Corte de Justicia integrada por nueve jueces y dos fiscales, ${ }^{20}$ establecía en su artículo 122 que esta se dividiría en dos salas para el conocimiento de causas relacionadas con la competencia originaria y exclusiva asignada a ese Tribunal. ${ }^{21} \mathrm{Y}$, a renglón seguido, aclaraba que la primera sala "compuesta de tres de sus miembros, conocerá de la primera instancia; y la otra sala, compuesta de los seis miembros restantes, conocerá de la segunda, y última instancia". ${ }^{22}$

Los escuetos fundamentos de esta división en salas de la Alta Corte de Justicia fueron desarrollados en la sesión del 7 de noviembre de 1826. Allí se expuso como argumento principal que "para las causas privilegiadas que originariamente por la Constitución debían iniciarse ante ella, sería menester también hacer dos o tres Salas porque estos juicios no debían terminar en una sola instancia” (Ravignani, 1937, pp. 1082-1084). Cabe destacar que en esa misma sesión el convencional Valentín Gómez advirtió que el aumento del número de jueces de la Alta Corte causaría varios inconvenientes "entre otros, la demora que el mayor número de ellos inferiría a los asuntos, teniendo que considerarlos particularmente" (Ravignani, 1937, p. 1082). ${ }^{23}$ Ravignani recuerda, además, que una de las objeciones fue "la posibilidad de dos fallos contradictorios emanados del supremo poder judicial” Ravignani (1927, p. 187).

20 Ver artículos 110 y 111 de la Constitución de 1826 en Constitución de la República Argentina sancionada por el Congreso General Constituyente el 24 de diciembre de 1826 y el Manifiesto que se remite a los pueblos para su aceptación (1826, p. 37).

21 La competencia originaria y exclusiva asignada por la Constitución de 1826 a la Alta Corte de Justicia surge de sus artículos 118 a 121: "Art. 118. Conocerá originaria y exclusivamente en todos los asuntos, en que sea parte una provincia, o que se susciten entre provincia y provincia, o pueblos de una misma provincia, sobre límites, y otros derechos contenciosos, promovidos de modo que deba recaer sobre ellos formal sentencia. Art. 119. En las cuestiones que resulten con motivos de contrato, o negociaciones del Poder Ejecutivo, o de sus agentes, bajo su inmediata aprobación. Art. 120. En las causas de todos los funcionarios públicos de que hablan los artículos 19, 27, 28 y 29, y respecto de los casos en ellos indicados. Art. 121. En las que conciernan a los embajadores, ministros plenipotenciarios, enviados, cónsules, y agentes diplomáticos de las cortes extranjeras" (Cfr. Constitución de la República..., 1826, p. 38).

22 Ídem.

23 Para profundizar el análisis acerca de la regulación de los tribunales en la Constitución de 1826, ver Valenzuela Beltrán (1967, p. 57). 
A pesar de que la Constitución de 1826 adoptó la separación de poderes de la Constitución de Filadelfia de 1787, ${ }^{24}$ la influencia de la Constitución de Cádiz en el diseño del Poder Judicial fue notable. Por una parte, no es un dato menor que la Constitución de 1826 no incluyera la competencia prevista en el actual artículo 116 de la Constitución Nacional referida a todos los puntos regidos por la Constitución y las leyes de la Nación con la reserva de los Códigos de fondo. ${ }^{25}$ Por la otra, los artículos 123, 124, 125 y 126 siguieron de cerca las atribuciones que la Constitución española de 1812 le otorgaba al Supremo Tribunal. Además, el artículo 127 dispuso, al igual que el 161, Décimo de la constitución gaditana, que la Alta Corte de Justicia "[i]informará de tiempo en tiempo al cuerpo Legislativo de todo lo conveniente para la mejora de la administración de justicia; y elevará todas las dudas, que le propusiesen los demás Tribunales, sobre la inteligencia de las leyes" (Constitución de la República..., 1826, p. 39).

La Constitución de 1826 no tuvo vigencia práctica. Sin embargo, constituyó un importante antecedente que influyó en varios puntos de la Constitución Nacional, con excepción de lo previsto en materia de organización judicial. A su vez, la influencia de la Constitución de Cádiz en el poder judicial desapareció totalmente al momento de sancionarse la Constitución Nacional en 1853. El modelo seguido por el constituyente, primero en 1853 y luego en 1860, sería radicalmente distinto.

\subsection{El debate de la Ley 182 (1858)}

A la hora de diseñar el Poder Judicial en la Constitución Nacional, los constituyentes de 1853 y 1860 siguieron al pie de la letra a la Constitución de los Estados Unidos. Esta cuestión se puso de manifiesto de forma contundente, especialmente durante el debate de la primera ley de Organización del Poder Judicial de la Confederación en 1858. Para confirmar el grado de influencia que tuvo el modelo norteamericano en este punto, basta citar la opinión de Juan María Gutiérrez durante el debate legislativo de la Ley $182 .{ }^{26}$ El célebre "vocero de Alberdi" en la Convención Constituyente de Santa Fe afirmó que:

24 Cfr. carta de John Forbes, Encargado de Negocios de los Estados Unidos en Buenos Aires, a Henry Clay, Secretario de Estado del Gobierno estadounidense, 15/7/1826, en Quesada Zapiola (1948, p. 174).

25 Cfr. Giménez Bonet (1947, p. 16).

26 Para profundizar el análisis acerca de la influencia del sistema constitucional estadounidense en el pensamiento de Gutiérrez y otros constituyentes de 1853 y 1860, ver García-Mansilla y Ramírez Calvo (2008, pp. 143 y ss.). 
Todas mis ideas son tomadas de las doctrinas del pueblo Norte-Americano y de su ciencia política. Debo recordar también que el Poder Judicial tal como ha sido establecido por nuestra Constitución es una copia exacta del Poder Judicial de la Unión Americana. [...] Nosotros no podemos menos de aceptar este poder en el sentido Norte-Americano, desde el momento que hemos dado a nuestro Gobierno la misma forma que aquél. (Congreso Nacional. Actas de las sesiones..., 1891, p. 522) $)^{27}$

La marcada influencia del constitucionalismo norteamericano es, insisto, indesmentible. También lo es el abandono total tanto del modelo gaditano como el de la Constitución de 1826 en lo relativo al Poder Judicial. En ese contexto es que se rechaza la primera propuesta de dividir a la Corte en salas luego de sancionada la Constitución Nacional, presentada en solitario por el diputado Emiliano García al momento de discutirse la Ley 182.

En la sesión de la Cámara de Diputados del 19 de julio de 1858, el diputado García intentó convencer a sus pares acerca de la necesidad de dividir a la Corte Suprema en dos salas para los casos de competencia originaria y exclusiva. En ese momento, se discutía el artículo 14 del proyecto de ley que, en consonancia con lo establecido en el artículo 98 de la Constitución de 1853, establecía que

[c]orresponde a la Suprema Corte de Justicia originaria y exclusivamente el conocimiento y decisión de las causas concernientes a Embajadores, Ministros y Cónsules extranjeros; en las que una provincia fuese parte, y en los conflictos entre los poderes públicos de una misma provincia. (Congreso Nacional. Actas de las sesiones..., 1891, p. 556)

\section{El diputado García propuso reemplazar esa redacción y agregar}

un artículo en lugar del que se discute, para que en los casos a que este se refiere, la Suprema Corte se divida en dos Salas, para que la una haga de Tribunal de 1a. instancia y la otra conozca en el recurso de súplica. (Congreso Nacional. Actas de las sesiones..., 1891, p. 557)

El exconvencional constituyente de 1853 y entonces ministro de Justicia, Culto e Instrucción Pública, Juan del Campillo, se opuso a esta propuesta de división en salas de la Corte. Sin embargo, aclaró que el recurso de súplica podía ser previsto por la propia Corte en su reglamento de procedimientos.

27 Sesión del 14 de julio de 1858. 
Con esa breve explicación, la propuesta de división del diputado García fue descartada y el artículo 14 del proyecto de ley fue aprobado por unanimidad. ${ }^{28}$

\subsection{El debate de la Ley 4055 (1901)}

En la sesión de la Cámara de Diputados de la Nación del 29 de noviembre de 1901, el Diputado Manuel Argañaraz propuso aumentar el número de jueces de la Corte Suprema y dividirla en tres salas para que "conozca de las causas de jurisdicción apelable" (Diario de Sesiones..., 5ª sesión de prórroga, 1901, p. 433). Se discutía en ese momento la que terminaría siendo la Ley 4055 que creó las Cámaras Federales de Apelación y redujo así la competencia apelada de la Corte Suprema. El diputado Argañaraz presentó un dictamen en minoría dado que creía que esa creación de tribunales intermedios era inconstitucional y no resolvía el problema de acumulación de causas en la Corte que se convertiría en una "tercera e inevitable instancia". ${ }^{29}$ Para Argañaraz, la apelación ante la Corte Suprema tenía que ser la regla y no la excepción. ${ }^{30}$ Por eso, consideraba que la creación de las Cámaras Federales de Apelación solo iba a alargar innecesariamente los procesos judiciales.

Argañaraz planteaba que la ampliación de la Corte y su división en salas no alteraban la unidad del tribunal:

Se mantiene la unidad por razón de la presidencia que lleva la dirección de todo el tribunal, de toda la corte suprema de justicia; se mantiene por razón de la superintendencia que esta ejerce sobre toda la administración de justicia nacional, y finalmente, porque constituida en corte plena, o por lo menos con mayoría absoluta de miembros, vendría a conocer en todas aquellas causas de jurisdicción originaria establecida por la constitución en aquellas que, como fiel y supremo intérprete de la misma constitución, de las leyes de la nación y los tratados con las potencias extranjeras, está llamada a mantener la uniformidad de la jurisprudencia. (Diario de Sesiones..., 5a sesión de prórroga, 1901, p. 435)

Además, según el diputado santiagueño, la Constitución no prohibía este tipo de propuestas:

28 Ver Congreso Nacional. Actas de las sesiones... (1891, p. 556).

29 Ídem.

30 Ver Diario de Sesiones... (5 sesión de prórroga, 1901, p. 434). 
no hay disposición alguna en la constitución que obste a que el congreso, con la facultad reglamentaria que le confiere el 101, divida la corte en varias salas, a fin de que conozcan de todas las causas apeladas. Siempre será la corte suprema la que entienda y decida de todas ellas por una parte de sus miembros constituidos en tribunal, de acuerdo con la ley reglamentaria, y se habrá conseguido que, dividido equitativamente el trabajo entre las tres salas, se obtenga la más pronta solución de todas las causas apeladas, con más rapidez todavía de la que se conseguiría con dos cámaras de apelaciones. (Diario de Sesiones..., 5a sesión de prórroga, 1901, p. 435)

Argañaraz citó en apoyo de su propuesta el ejemplo de países europeos, incluyendo Francia y su tribunal de casación, así como el ejemplo de los tribunales superiores de la provincia de Córdoba y de Santa Fe. ${ }^{31}$ En definitiva, desde la visión centralista del diputado por Santiago del Estero, sería imperdonable

el error en que incurriríamos rompiendo uno de los vínculos de esta nacionalidad aún incipiente, al destruir la unidad de jurisprudencia en un país regido por ella y substancialmente por una misma legislación de fondo desde los remotos tiempos de la conquista. (Diario de Sesiones..., 5a sesión de prórroga, 1901, p. 436)

La propuesta de Argañaraz fue contestada por el diputado Juan Balestra, quien, como miembro informante del despacho de mayoría de la Comisión de Justicia, explicó que

aquí se presentan dos sistemas: uno propone dividir la Corte en tres salas; el otro propone crear dos cortes intermedias, dos cámaras federales de apelación [...]. [L]a comisión ha juzgado que una corte de diez miembros que pudiera dividirse en tres salas, podría dividirse en cuanto a las personas; pero no podría trabajar al mismo tiempo como corte y como cámara de apelación; y cuando el trabajo que se exigiera fuera tan grande que requiriera el trabajo de toda la corte constantemente y de todas las cámaras constantemente, también para despejar esa situación de hecho y por lo mismo gravísima, pues sin liquidarla es imposible seguir adelante, sucedería que mientras estas tres cámaras en que se dividiera la corte estuvieran trabajando como cámara, sería necesario a la vez que estuvieran trabajando como corte, y aparte de que una corte de diez miembros despacharía con más dificultad que una de cinco, -o la corte o esas cámaras tendrían indudablemente que interrumpir sus tareas-, queriéndose hacer el trabajo rápido, se produciría por el contrario una obstaculización tal, que en definitiva no habríamos hecho sino ampliar los tribunales echándoles encima una situación

31 Ver Diario de Sesiones... (5 sesión de prórroga, 1901, p. 437). 
insoluble hoy, que sería igualmente insoluble mañana. (Diario de Sesiones..., 5a sesión de prórroga, 1901, p. 431)

El ministro de Justicia, Juan Serú, también rechazó la división en salas propuesta por Argañaraz:

El señor diputado se esforzaba por hacer comprender que la acción de una sala constituida de tres miembros era la expresión del conjunto de la suprema corte, y que no podía haber aplicación distinta de doctrinas entre una sala con la otra. No, señor presidente. No comprendo que pueda llegarse a esta conclusión, de que se ha de mantener mayormente el espíritu de unidad en un tribunal que se divide en salas para hacer el despacho de todos sus asuntos, que en un tribunal que se conserva sobre todos los tribunales de menor jerarquía en su número ordinario, tal como fue constituido en los orígenes de la organización de esta justicia. (Diario de Sesiones..., 5a sesión de prórroga, 1901, pp. 439-440)

Finalmente, el autor del proyecto de ley, el diputado Julián Barraquero, rechazó los argumentos expuestos por Argañaraz en estos términos:

En primer lugar, los autores, constitucionalistas o juristas, que ha citado el miembro informante de la minoría de la comisión, no se refieren absolutamente al derecho común, a los asuntos del fuero ordinario. En Estados Unidos como aquí, la jurisprudencia que establece y mantiene la corte suprema es la jurisprudencia para los asuntos del fuero federal, del fuero constitucional; aquí como allí el poder judicial no tiene un rol simplemente judiciario, como lo tiene en las naciones europeas: la institución americana del poder judicial es una institución verdaderamente nueva en el mundo; es una institución, como muy bien lo ha dicho el señor ministro, de orden político. La corte federal no se creó especialmente para fallar los asuntos del fuero común, para mantener la jurisprudencia de los códigos civil, de comercio y de minería; no, señor presidente. Esa corte federal está para mantener dentro de su órbita respectiva a los poderes del estado. (Diario de Sesiones..., 5a sesión de prórroga, 1901, p. 440)

A renglón seguido, haciendo hincapié en las peculiaridades de la forma de gobierno federal de la Constitución de 1853/60, Barraquero explicó que

[n]uestra constitución, si bien ha hecho una excepción al principio federativo y ha establecido que no sean los estados argentinos los que dicten los códigos civil, de comercio y de minería, sino que sea el congreso, haciendo una desviación a los principios del federalismo, ha establecido también que son las provincias las que aplicarán esos códigos en los casos del fuero común. ¿Y cómo podría 
entonces la suprema corte mantener la unidad de la jurisprudencia en estos asuntos? De ninguna manera [...]. ¿[S]e puede sostener que una corte compuesta de nueve miembros, dividida en salas, puede ser a la vez corte suprema para las causas que correspondan a la corte y cámara o salas para las causas de apelación? Naturalmente que no; mientras la corte dividida en salas está estudiando los asuntos que se refieran a esas salas, en ningún caso puede, por ningún arte, por ninguna invención, a la vez, reunirse y ser corte para fallar los asuntos que a la corte corresponden. Es pues, un mecanismo que no puede dar buen resultado. (Diario de Sesiones..., 5ª sesión de prórroga, 1901, pp. 440-441)

Aprobado el proyecto de ley, el Senado no trató la propuesta de división en salas porque, en palabras del senador Dámaso Palacio,

yo no discutiré la bondad de este proyecto de organización, cuyo exponente autorizado y sincero ha sido en estos días en la Cámara de Diputados el doctor don Manuel Argañaraz, y no lo discutiré, porque ha sido siempre un propósito que no ha tenido aceptación en el público, en el seno de los poderes del Estado, ni en las Cámaras del Congreso. (Diario de Sesiones..., 23ª sesión de prórroga, 1901, p. 580)

\subsection{El proyecto de reforma constitucional del Gobierno de facto (1930)}

Casi treinta años después, a pocos días de producido el golpe de Estado del 6 de septiembre de 1930, el llamado "Gobierno provisional" avisó que propondría una reforma constitucional. ${ }^{32}$ Esa reforma sería publicitada el 18 de junio de 1931. Según el Gobierno de facto, "la Revolución de Septiembre tiene un contenido mucho más hondo y fundamental que un simple cambio de hombres en el gobierno. Se imponen reformas substanciales en algunas de nuestras instituciones" (La obra de la Revolución..., s.f., p. 196). Entre esas reformas se incluía a la Corte Suprema y a su división en salas.

El Gobierno militar planteó que

contra la anarquía en la aplicación de la ley en todo el territorio de la Nación, y para afianzar la justicia, evitando que influencias políticas o de otro orden se infiltren en los tribunales de provincia, es indispensable dar a la Suprema

32 Ver Manifiesto del Excmo. Señor Presidente del Gobierno Provisional de la Nación, Teniente General don José F. Uriburu (1930, pp. 47 y ss.). Para un análisis general sobre el proyecto de reforma constitucional del Gobierno de facto, ver Frontera (1995, pp. 95 y ss.). 
Corte, ampliándola, funciones de Tribunal Superior de Casación en los casos de violación o inaplicabilidad de la ley común. (La obra de la Revolución..., s.f., pp. 198-199)

Entre las reformas "más urgentes e inmediatas" que nuestro sistema demandaba, se incluía el elevar a no menos de quince la cantidad de jueces de la Corte Suprema y dividirla en dos salas. La creación de una "Corte Suprema Federal y de Casación” se haría a través de una reforma al artículo 100 de la Constitución Nacional de 1853/60, que pasaría a tener la siguiente redacción:

La Corte Suprema estará compuesta de un Presidente, de un número de ministros no menor de catorce y de un procurador general y se dividirá en dos salas con el número de miembros que para cada una fije la misma Corte en el reglamento a que se refiere el artículo 99. Una de las salas conocerá de las causas federales y de las provincias, de los recursos extraordinarios y de las cuestiones institucionales y de la reforma del $5^{\circ}$. [sic]; ${ }^{33}$ y la otra sala funcionará como Corte de Casación cuya competencia y procedimiento serán reglamentados por la ley. (La obra de la Revolución..., s.f., p. 205)

La exposición de motivos del proyecto de reforma constitucional en cuestión concluía que

en esta forma el Tribunal Supremo será una Corte Federal y de Casación que realizará el verdadero afianzamiento de la justicia a que se refiere el preámbulo de la Constitución y el artículo $5^{\circ}$ en todo el territorio de la Nación, y en todas las jurisdicciones, tanto en lo que se refiere a la interpretación y aplicación de la Constitución y de las instituciones políticas provinciales y federales, cuanto en lo que se relaciona con la aplicación de la ley común por todos los tribunales del país. (La obra de la Revolución..., s.f., p. 205)

Si bien el proyecto de reforma constitucional del Gobierno de facto de 1930 quedaría trunco, uno de sus funcionarios y adherentes más notorios insistiría años después con la propuesta.

33 La referencia al artículo 5 se refiere a la propuesta del Gobierno de facto para que la Corte interviniera para garantizar la autonomía de las provincias. El artículo 5 del proyecto de Constitución establecía: "Bajo estas condiciones cada provincia tendrá el goce y ejercicio de sus instituciones, cuya violación será resuelta con un procedimiento sumario por la Corte Suprema Nacional como tribunal encargado de interpretar en último término la Constitución y de hacer predominar sus principios en casos de conflictos institucionales" (La obra de la Revolución..., s.f., p. 199). 


\subsection{El proyecto de reforma constitucional de Ibarguren (1948)}

En 1948, en el marco del llamado a la reforma de la Constitución de 1853/60 durante el primer Gobierno del Gral. Juan D. Perón, Carlos Ibarguren (1948, p. 69) propuso un proyecto de reforma constitucional que incluía una Corte Suprema organizada en tres salas de cinco miembros cada una.

Ibarguren (1948) aclaraba que en su proyecto de reforma de la Constitución

la jurisdicción proyectada para la Suprema Corte Nacional es vasta y versa sobre asuntos políticos y jurídicos trascendentales. No se circunscribe, como es la actual, a la decisión de casos puramente judiciales, sino que se extiende a un campo mucho más amplio. La Corte que propongo es el cuerpo que mantiene la regularidad en todos sus aspectos y el árbitro que debe dirimir los graves conflictos que se suscitaren entre los poderes del Gobierno Nacional, o de éste con las provincias, o los que se produjeren entre las mismas. [...] Por último, es Corte de Casación que entiende también por vía de recurso, en las condiciones y de acuerdo con lo que estatuyan las leyes, de las sentencias de los tribunales del país para uniformar la jurisprudencia en la aplicación e interpretación de los Códigos, de la legislación común y de las leyes federales. (pp. 69-70)

El artículo 87 del proyecto de constitución de Ibarguren (1948) establecía que "La Corte Suprema de la Nación se compondrá de quince miembros, dividida en tres salas de cinco miembros cada una" (p. 124). A su vez, el artículo 89, inciso 4 del proyecto establecía que

Son atribuciones de la Suprema Corte: [...] 4. Los recursos de casación contra sentencias definitivas de los tribunales nacionales y provinciales, en los casos en que según las leyes correspondan esos recursos, en los que la Corte procederá como Tribunal Supremo de Casación. (Ibarguren, 1948, pp. 124-125)

A pesar de la insistencia de Ibarguren, que reciclaba la propuesta del Gobierno de facto de 1930, la iniciativa no tuvo éxito y no fue seguida durante la Convención constituyente reformadora de 1949 en cuanto a la división de la Corte Suprema en salas. Sin embargo, sí tuvo eco en relación con la propuesta de convertir a la Corte en un tribunal de casación. De hecho, en su parte pertinente, el artículo 95 de la Constitución de 1949 dispuso que:

La Corte Suprema de Justicia conocerá, como Tribunal de Casación, en la interpretación e inteligencia de los códigos a que se refiere el inciso 11 del artículo 68. La interpretación que la Corte Suprema de Justicia haga de los artículos de la Constitución por recurso extraordinario, y de los códigos y leyes por recurso 
de casación, será aplicada obligatoriamente por los jueces y tribunales nacionales y provinciales. Una ley reglamentará el procedimiento para los recursos extraordinario y de casación, y para obtener la revisión de la jurisprudencia. (Sampay, 1949, pp. 149-150)

\subsection{El debate de la Ley 15271 (1960)}

Quien sí tuvo éxito en su propuesta de dividir a la Corte en salas fue Arturo Frondizi. Doce años después de la propuesta de Ibarguren, impulsó la sanción de la Ley 15271, cuyo artículo 1 previó la ampliación de la composición de la Corte Suprema para llevarla a siete jueces. A su vez, facultó concretamente al Tribunal a que se dividiera en salas:

Deróganse los artículos 19, 21, 23 y el apartado a) del inciso $6^{\circ}$ del artículo 24 del Decreto-Ley 1.285 del 4 de febrero de 1958 y se los sustituye por los siguientes: [...] Artículo 21. La Corte Suprema de Justicia estará compuesta por siete jueces y un procurador general. Tendrá su asiento en la Capital Federal y designará su presidente. Dictará su reglamento interno y económico y el reglamento para la justicia nacional, estableciendo las facultades de superintendencia de la Corte Suprema y tribunales inferiores. Art. 23. Facúltase a la Corte Suprema de Justicia a dividirse en salas, de acuerdo al reglamento que a tal efecto dicte. Hasta que el mismo no esté en vigencia, las decisiones de la Corte Suprema se adoptarán por el voto de la mayoría absoluta de los jueces que la integran, siempre que éstos concordaren en la solución del caso; si hubiere desacuerdo, se requerirán los votos necesarios para obtener la mayoría absoluta de opiniones. La Corte actuará en tribunal pleno en los asuntos en que tiene competencia originaria y para resolver las cuestiones de inconstitucionalidad. [...]. ${ }^{34}$

Vale la pena repasar la génesis del único antecedente en el que se concretó normativamente la autorización para que la Corte se dividiera en salas después de sancionada la Constitución Nacional. ${ }^{35}$ El 18 de agosto de 1958, pocos días después de asumir la Presidencia de la Nación, Frondizi envió un oficio a la Corte Suprema para "conocer la opinión de la Corte Suprema de Justicia de la Nación, acerca de la oportunidad y conveniencia de aumentar el número de jueces que la integran, con asignación de Salas de competencia determinada” (Bielsa, 1958, p. 319). ${ }^{36}$ Ese oficio fue contestado favorablemente a través de

34 BO 9/02/1960, http://servicios.infoleg.gob.ar/infolegInternet/verNorma.do?id=114501.

$35 \mathrm{Al}$ respecto, ver Oyhanarte (2013, pp. 672-679).

36 Bielsa publicó este artículo con el sobrenombre "Próculo". 
una Acordada de fecha 25 de agosto de 1958. ${ }^{37}$ Allí, la Corte, con la disidencia del juez Aráoz de Lamadrid, planteó que

esta Corte Suprema considera de toda necesidad y urgencia aumentar a nueve el número de miembros del Tribunal, en consideración al elevado monto de causas que durante los diez años últimos, sobre todo, han llegado regularmente al conocimiento de la Corte [...]. Las estadísticas de los últimos años revelan que el Tribunal viene soportando el peso de una elevada cantidad de causas que no logran ser resueltas, junto con las que ingresan cada año, no obstante el trabajo constante y empeñoso de Jueces y secretarios [...]. Todo esto solo puede remediarse con una reforma sustancial en la estructura de la Corte que, al mismo tiempo que aumente el número de sus jueces y secretarios, haga posible la división en Salas a fin de dar pronto despacho a un gran número de causas (expropiaciones, cuestiones de réditos o aduanas, etc.) que no constituyen el trabajo realmente propio de una Corte Suprema. ${ }^{38}$

Repitiendo los argumentos expuestos en la Acordada en cuestión, el 13 de julio de 1959, el presidente Frondizi envió al Congreso un proyecto de ley que proponía el aumento del número de jueces de la Corte y su división en salas. ${ }^{39}$

En la Cámara de Diputados de la Nación, el diputado por la provincia de Corrientes, Porfirio Aquino, fue el encargado de defender el proyecto de ley con las modificaciones introducidas por la Comisión de Justicia. Luego de hacer una larga exposición acerca de los orígenes e importancia del Poder Judicial, en relación con la propuesta de dividir en salas a la Corte, Aquino citó a las constituciones de Colombia, Costa Rica, Venezuela y México como antecedentes del derecho comparado "que atañen a las bases de este proyecto" (Diario de Sesiones..., 86ª reunión, 1960, p. 6460). Y, a renglón seguido, planteó que "a esta altura quiero hacer una ligera referencia a las circunstancias que hacen necesaria la modificación del número de jueces y la división en salas. Los dos presupuestos se encuentran armónicamente entrelazados" (Diario de Sesiones..., 86a reunión, 1960, p. 6461). Aquino sostuvo que la división en salas iba a facilitar las tareas del tribunal, que tenía un déficit de trabajo acumulado a raíz de la multiplicación de causas. Y aclaró que el proyecto dejaba a salvo los asuntos de competencia originaria y en los que se resolviera la inconstitucionalidad de una

37 Aumento del número de jueces de la Corte Suprema, Fallos: 241:112 (1958).

38 Aumento del número de jueces de la Corte Suprema, Fallos: 241:112, p. 113 (1958).

39 Ver Diario de sesiones... (86ª reunión, 1960, pp. 6454-6455). 
ley nacional, provincial o un decreto del Poder Ejecutivo que requerirían la actuación de la Corte en pleno (Diario de Sesiones..., 86ª reunión, 1960, p. 6461). A su turno, el diputado Augusto Vecchietti argumentó que

la Corte resolvió que era conveniente el aumento del número de jueces, a fin de que el tribunal pudiera dividirse en salas. La importancia y la razón del aumento del número de jueces de cinco a siete se funda precisamente en la necesidad de esa división en salas, que facilitaría extraordinariamente el funcionamiento de la Corte, donde existen gran cantidad de asuntos demorados en más de un año después del llamamiento de autos para sentencia. Quiere decir que el aumento del número de jueces constituye un evidente auxilio para la Corte Suprema de Justicia [...]. (Diario de Sesiones..., 86ª reunión, 1960, p. 6461)

\section{Y más adelante agregó que}

el propósito que persigue este proyecto, al aumentar el número de jueces de cinco a siete, no es desde luego el de incorporar nuevos jueces a la Corte Suprema, sino el deseo de permitir su división en salas, que no es posible con el número actual de miembros. En cambio, con siete jueces sería factible tal división [...]. (Diario de Sesiones..., 86 reunión, 1960, p. 6462)

Vecchietti intentó despejar las dudas acerca de la constitucionalidad del proyecto de ley:

entendemos que la división del alto tribunal en salas no afecta ni el espíritu ni la letra de nuestra Constitución, ya que no surge de ella ninguna disposición que permita considerar inconstitucional esta iniciativa. En todas sus normas se habla de la Corte Suprema como organismo, pero en ninguna parte se establece cuál será su funcionamiento, ya que es atribución del Congreso y de ella misma el modo y forma como ha de desenvolver su trabajo. Por lo demás, [...] los antecedentes históricos nacionales que han dado origen a nuestra Constitución demuestran que ya había sido prevista la división en salas, como en la Constitución de 1826, que habla textualmente de ella. (Diario de Sesiones..., 86ª reunión, 1960, p. 6463)

\section{Y remató su exposición observando que}

no creemos que esta reforma que propiciamos altere, modifique o viole en lo mínimo [sic] la Constitución Nacional, pues la Corte Suprema, cuya acordada también propicia esa división en salas, con toda seguridad habría advertido ese impedimento constitucional, de haber existido. (Diario de Sesiones..., 86 ${ }^{\mathrm{a}}$ reunión, 1960, p. 6463) 
A renglón seguido, el diputado César Lagos sostuvo que en la Constitución de 1826 ya figuraba la facultad de la Corte Suprema de dividirse en salas "a los efectos de una mejor organización del trabajo, sistema que desapareció en la Constitución de 1853 y en la reforma de 1860" (Diario de Sesiones..., 86a reunión, 1960, p. 6464).

El diputado Ernesto López Sansón, a su vez, afirmó que

la división en salas, cuando no se trate de la interpretación de una norma constitucional o de asuntos originarios, resultará de beneficio público, pues se agilizará el trámite del proceso en bien de los propios litigantes [...]. La Corte actuará en pleno cuando se trate de considerar problemas constitucionales o de competencia originaria. No podría ser de otra manera, pues nosotros no podemos evadir las disposiciones constitucionales que se hallan vigentes y que solo pueden ser derogadas por una Convención. (Diario de Sesiones..., 86ª reunión, 1960, p. 6469)

El diputado Antulio Pozzio también defendió la división en salas argumentando que había un precedente similar en la provincia de Buenos Aires. Y a continuación aclaró que

no desconozco que existe una corriente contraria a esta división en salas, por entender que cuando el artículo 94 [hoy artículo 108] habla de "una" Corte nacional quiere referirse a la integridad de todos sus miembros, por lo que ella no podría ser dividida en salas. [...] Nosotros creemos que las argumentaciones no son valederas, que no hay impedimento de orden constitucional para la división en salas. (Diario de Sesiones..., 86ª reunión, 1960, p. 6474)

Finalmente, el diputado Oscar López Serrot juzgó que la división en salas era "indispensable", ya que, de otro modo, el aumento del número de jueces en la Corte "provocaría mayores demoras desde que de no mediar tal subdivisión tendrían que expedirse mayor cantidad de jueces" (Diario de Sesiones..., 86a reunión, 1960, p. 6479).

Una de las pocas voces críticas en la sesión del 12 de enero de 1960 fue la de diputado Adolfo Contte (h), quien destacó que

nuestros antecedentes legislativos están en favor del establecimiento de una Corte de una sala, y éste es uno de los puntos en los cuales disiento con el proyecto de la comisión, porque allí se autoriza a desdoblar la Corte en dos salas que actuarán en determinadas circunstancias y condiciones. [...] Considero inadecuada e inconstitucional la división de la Corte Suprema en dos salas. (Diario de Sesiones..., 86ª reunión, 1960, p. 6467) 
Al día siguiente, en la sesión del 13 de enero de 1960, el diputado Porfirio Aquino defendió nuevamente la división en salas. Para ello, invocó el debate del 29 de noviembre de 1901, en especial la opinión vertida por Manuel Argañaraz, aunque omitió cualquier referencia a las opiniones contrarias del autor de la Ley 4055, Julián Barraquero (Diario de Sesiones..., 87a reunión, 1960, p. 6526).

Una vez aprobado, el proyecto de ley fue girado al Senado, que lo trató en una brevísima sesión el 3 de febrero de 1960. En esa ocasión, el senador Víctor Hugo Fleitas fue el único orador. Fleitas defendió la división en salas apelando al antecedente del artículo 122 de la Constitución de 1826, al que consideraba "muy valioso" (Diario de Sesiones..., 81ª reunión, 1960, p. 3287). También citó en apoyo de la división tanto a la Acordada del 25 de agosto de 1958 como a la propuesta de reforma constitucional de 1931 presentada por el Gobierno de facto de Uriburu. Y remató su peculiar exposición planteando que

\begin{abstract}
creemos, pues, a la luz de los antecedentes expuestos, que la división en salas que propicia el proyecto no es contraria ni al texto ni al espíritu de la Constitución, ya que de su lectura no surge ninguna disposición que pueda dar motivo a considerar esta solución como inconstitucional. Por el contrario, de sus normas surge que queda reservado al Congreso y a ella misma la facultad de reglar su funcionamiento y la forma de desarrollar sus tareas. Recurriendo al derecho comparado observamos que en varias repúblicas americanas se autoriza la división en salas de sus más altos tribunales de justicia, ya sea por mandato constitucional o por disposición de las leyes que dicten sus respectivos Parlamentos, como Colombia, Costa Rica, Venezuela, Brasil, México y otras. (Diario de Sesiones..., 81ª reunión, 1960, pp. 3288-3289)
\end{abstract}

A pesar de considerar "de toda necesidad y urgencia" 40 tanto el aumento de sus integrantes como su división en salas para lidiar con la sobrecarga de tareas, después de sancionada la Ley 15271 y de ingresados los nuevos jueces después de la ampliación de sus integrantes, la Corte Suprema jamás hizo uso de la facultad concedida para dividirse en salas. ${ }^{41}$

\title{
2.7. El proyecto de ley de organización de la Corte Suprema de Illia (1964)
}

El último antecedente identificado en esta investigación es el intento de am-

40 Aumento del número de jueces de la Corte Suprema, Fallos: 241:112, p. 113 (1958).

41 De hecho, la Corte Suprema rechazó planteos judiciales que pretendían cuestionar decisiones tomadas por la mayoría absoluta de los integrantes de la Corte y no el pleno, es decir, todos los 
pliación de la Corte Suprema durante el Gobierno de Arturo Illia. El 7 de julio de 1964, con la firma del presidente Illia y de su ministro de Justicia y Educación, Carlos Alconada Aramburú, el Poder Ejecutivo envió un proyecto de ley de Organización y Competencia de la Corte Suprema de Justicia. El proyecto proponía ampliar a diez el número de jueces de la Corte Suprema y regulaba el procedimiento para su división en tres salas de tres jueces cada una. ${ }^{42}$

El proyecto pretendía fundarse en "la necesidad de aumentar la eficacia del funcionamiento de la administración de justicia" (Organización y Competencia..., 1964, p. 6) y apelaba a una peculiar revisión del "derecho comparado americano" que, supuestamente, demostraba "que el actual número de jueces de la Corte nacional tampoco se halla en consonancia con lo que constituye el fondo común legislativo en la materia" (Organización y Competencia..., 1964, p. 7). Así, se citaban solamente los casos de Perú, Colombia, Bolivia y México, pero se descartaba de plano al modelo estadounidense seguido por la Constitución Nacional porque se alegaba que había perdido "mérito comparativo" (Organización y Competencia..., 1964, p. 7).

El 24 de julio de 1964, la Comisión de Interior y Justicia del Senado de la Nación envió una consulta a la Corte, que fue respondida dos semanas después. ${ }^{43}$ Allí, la Corte informó que se había acordado un texto de respuesta y que había sido encomendado al presidente, Aristóbulo Aráoz de Lamadrid. El 10 de agosto de 1964, Aráoz de Lamadrid presentó al Senado una extensa nota -que incluía un anexo con un detallado informe estadístico- en la que respondió que la ampliación era innecesaria. ${ }^{44}$

La Corte Suprema observó que la "pertinencia" de la facultad de determinar el número de sus miembros, que efectivamente tiene el Congreso, está supeditada a que su ejercicio responda a una exigencia concreta de "las necesidades reales” del tribunal. Luego de señalar, con cita a autores estadounidenses, que el incremento de jueces no aumenta la eficiencia del tribunal, la Corte sostuvo que

integrantes. En esos casos, la Corte sostuvo que "el Tribunal encuentra del caso agregar que la cláusula del art. 23 [sic] de la Ley 15.271 ha sido interpretada con el alcance que la exigencia de tribunal plenario allí prevista rige para el supuesto, aun no ocurrido, de la división en Salas de esta Corte, y autoriza las sentencias con participación de la mayoría absoluta de los jueces que la integran” (S.A. Alejandro Bianchi y Cía. v. Nación Argentina, Fallos: 248:398, considerando 4º p. 400; Julio Goldberg v. Orbe Films, Fallos: 248:442; Santiago Cardoso v. Ernestina Magna Sánchez de Llano y otros, Fallos: 262:300; etc.).

42 Ver Organización y Competencia... (1964, pp. 6-8).

43 Consulta de la Comisión de Interior y Justicia del H. Senado de la Nación, Fallos: 259:214 (1964).

44 Dado que en la colección de Fallos no se transcribe la nota del Presidente de la Corte, utilizo la publicada en Organización y Competencia... (1964, pp. 117-130). 
debe advertirse, y a solo título complementario, que el número de miembros de la Corte Suprema que fija el proyecto no parece compadecerse con las funciones decisorias propias de los órganos colegiados del Poder Judicial y excede el número contenido en las normas jurídicas o en las propuestas o proyectos conocidos en la historia legal y constitucional del país. (Organización y Competencia..., 1964, pp. 118-119)

A su vez, contradiciendo directamente lo que había dicho en la Acordada del 25 de agosto de 1958, la Corte advirtió que "su división obligatoria en salas minoritarias, esto es, con menos de la mayoría absoluta concordante de los jueces que integran el tribunal, es de constitucionalidad problemática" (Organización y Competencia..., 1964, p. 119). A renglón seguido aclaró que

es con esta reserva que ha de entenderse la acordada del 25 de agosto de 1958 de los entonces integrantes de esta Corte Suprema -Fallos 241:112- en cuanto allí se requirió explícitamente que la ley "haga posible la división en salas", y ello tan sólo para atender causas "que no constituyen el trabajo de una Corte Suprema". (Organización y Competencia..., 1964, p. 119)

\section{La Corte sostuvo que}

la labor de la Corte Suprema, incluyendo su tarea fundamental, difícilmente puede ser cumplida por un fracción minoritaria del tribunal, que podría reducirse a dos de sus miembros en los términos del proyecto [...]. No remedia la situación la posibilidad de convocatoria a tribunal plenario. Porque éste sólo parece posible cuando ya media jurisprudencia contradictoria y, en todo caso, no podría reabrir las causas fenecidas en que aquélla se ha establecido. Tampoco la remedia la no comprensible limitación del plenario que el proyecto propone respecto de las causas de inconstitucionalidad traídas tan sólo de tribunales provinciales, con lo que vendrían a quedar excluidas de aquel las sentencias de los tribunales y órganos jurisdiccionales nacionales, relativas a la actividad del gobierno nacional en el ámbito constitucional y federal. (Organización y Competencia..., 1964, pp. 119-120)

Y para rematar su rechazo a la división en salas, la Corte afirmó que "por lo demás, son notorias las dificultades y demoras que resultan de la práctica de las decisiones plenarias" (Organización y Competencia..., 1964, p. 120).

La Corte rechazó también los ejemplos extranjeros y locales que pretendían presentarse como argumentos en favor de la división en salas. En particular, advirtió que "la posibilidad de regímenes distintos, provinciales o extranjeros, 
con base en competencias diferentes -especialmente en materia de derecho común- no puede alterar la solución a que se llega en las consideraciones precedentes" (Organización y Competencia..., 1964, p. 120). Finalmente, en cuanto a la posible obligatoriedad de las decisiones plenarias, la Corte observó que

es igualmente problemática la conveniencia y el acierto del establecimiento de la obligatoriedad de la jurisprudencia plenaria de la Corte Suprema. Porque su necesidad, si es que existe, tendría razón eminente de ser en materia constitucional, y es allí precisamente donde es más cuestionable. (Organización y Competencia..., 1964, p. 120)

El 15 de agosto de 1964, el proyecto de ley fue aprobado por la Cámara de Senadores. ${ }^{45}$ Desoyendo la opinión de la Corte en cuanto al rechazo a la ampliación de sus integrantes, el Senado no solo aprobó el proyecto de ley enviado por Illia, sino que aumentó a once el número de jueces de la Corte. Sin embargo, eliminó el artículo que obligaba a su división en salas y no hubo defensa alguna de esa división durante el debate. El proyecto aprobado siguió su curso, pero, una vez ingresado a la Cámara de Diputados, nunca más fue tratado.

El antecedente mereció en su momento la crítica de Aja Espil (1964), quien sostuvo que

sin perjuicio de la interpretación estrictamente gramatical de los que ven en el art. 94 [hoy artículo 108] Const. Nac., una verdadera valla para el establecimiento de salas, consideramos que la Corte Suprema, en cuanto órgano constitucional con funciones de alta política, es decir como cabeza de poder, no admite tal innovación sin peligro de ofender facultades que le son propias. La frecuente mención que, con relación a este problema se hace respecto a otras altas Cortes de Justicia, ya europeas, ya americanas, no suele ser acertada. La función primordial en casi todas ellas se limita a la de administrar justicia. Pero nuestra Corte Suprema va más allá que a la mera solución de conflictos entre partes, ya que su alta función es la de fijar la interpretación final de la Constitución, en todos los tiempos y en cualquier emergencia. (p. 72)

\section{Opiniones doctrinarias}

La idea de la división de la Corte Suprema en salas ha concitado la atención de varios autores a lo largo de los últimos años, aunque pocos la han estudiado en

45 Ver Organización y Competencia... (1964, pp. 97-98). 
profundidad. Sin pretensión de exhaustividad, a continuación haré una reseña de las opiniones más importantes.

\subsection{Opiniones contrarias}

Bielsa (1958) rechazó la Acordada del 25 de agosto de 1958 argumentando que en la Corte Suprema la división en salas implicaría simplemente una instancia adicional, pero "sin la unidad que es esencial en la cima de toda jurisdicción" (p. 319).

Bidart Campos (1967) cuestionó también la división en salas:

estando directamente establecido por la constitución un órgano judicial máximo como Corte Suprema, y surgiendo su competencia también de la constitución, entendemos que la Corte no puede ser dividida en salas. Ello equivaldría a que sus sentencias fueran dictadas por una sala, y no por el tribunal en pleno. (p. 223) ${ }^{46}$

\section{Además, sostuvo que}

cuando la Corte entiende en un caso, entiende con fundamento constitucional, aunque medie válidamente reglamentación legal. Es decir, interviene como Corte, con todos sus jueces; si interviene con una de sus salas, no es la Corte de la constitución, y por ende, la constitución padece violación. (Bidart Campos, 1967, p. 223)

\section{César Enrique Romero (1976) también se pronunció en contra:}

se ha propuesto el aumento y la creación de salas dentro del Tribunal. Ese evento no parece congruente con la Constitución, quien ha explicitado que la cabeza del Poder Judicial es una "Corte Suprema”, que funcione como tal e integrada de sus miembros, o de su mayoría. Las salas de los tribunales colegiados desnaturalizan ciertamente su función, al dividir la actuación de sus miembros. (p. 277) ${ }^{47}$

Con una línea argumental similar, Linares Quintana (1987) sostuvo que la Corte

no admite su subdivisión en salas de competencia determinada. Una fragmentación semejante quitaría en el hecho a la Corte Suprema su rango de tal, y tendría

46 Énfasis en el original.

47 Énfasis en el original. 
como resultado práctico que sus decisiones ya no serían del primer tribunal del país sino de una sala determinada del mismo, con una evidente diferencia de jerarquía jurídica, que en manera alguna previeron los constituyentes argentinos. (p. 786)

Para este autor, la división del Tribunal Supremo en salas especializadas resulta absolutamente inconstitucional, ya que "ello quitaría a la Corte su carácter esencial de Tribunal Supremo, haciendo posible que las opiniones coincidentes solamente de dos ministros constituyan sentencia” (Linares Quintana, 1987, p. 787).

A su vez, en uno de los estudios más completos sobre el tema, Alberto Bianchi (1988) afirmó que

quienes están de acuerdo en dividir a la Corte en salas, no advierten que entre ella y las Cámaras de Apelación no solamente existe una diferencia de grado basada en la jerarquía superior de la primera, sino que existe también una diferencia cualitativa que hace que la Corte además de un Tribunal sea un Poder del Estado semejante y jerárquicamente igual a los otros. Esto quiere decir que cuando la Corte se pronuncia a través de sus sentencias (al igual que el Congreso lo hace a través de leyes y el Poder Ejecutivo por medio de actos administrativos individuales o generales) su decisión debe ser la del cuerpo todo, debe ser la decisión de "la" Corte como Tribunal y como Poder, pero no la de un grupo minoritario de personas, cuya decisión no refleja tal vez el pensamiento de los demás jueces que la integran. (p. 973)

Además, hizo el siguiente planteo:

[Q]ué diríamos si a un legislador se le ocurre, a efectos de dotar al Congreso de mayor agilidad, dividir a las cámaras legislativas en varias subcámaras de resultas de lo cual, en lugar de tener una de Senadores y una de Diputados, tuviéramos tres de cada una, con poder suficiente para sancionar leyes. El principio bicameral se respeta pues puede actuar la Cámara de Diputados No. 1, con la Cámara de Senadores también No. 1 y sancionar una ley que luego será promulgada. De tal forma tendremos tres Congresos y no uno y su actividad será mucho más rápida y efectiva. Se dirá inmediatamente que este ejemplo es ridículo y carece de andamiento, pues va en contra de la propia letra de la Constitución que prevé una sola Cámara de Diputados y una sola Cámara de Senadores. Esto es cierto, pero no lo es menos que tampoco la Constitución prevé expresamente la división en salas de la Corte y no creo que de la letra literal de la Constitución podamos obtener autorización para ello, en la medida que el art. 94 [hoy artículo 108] es muy claro, cuando dice que el Poder Judicial se ejercerá por "una Corte Suprema de Justicia” y los demás Tribunales inferiores que el Congreso estableciere en el 
territorio de la Nación. Es claro entonces que lo que la Constitución quiere es que "el Poder Judicial" sea ejercido por "una Corte Suprema” y no por alguna sala de esa Corte Suprema. (Bianchi, 1988, pp. 974-975)

Gregorio Badeni (2010) sostuvo que la división en salas generaría una pérdida de autoridad de la Corte y agregó que se traduciría en "una pluralidad de tribunales que no se compadece con el texto constitucional que hace referencia a una sola Corte Suprema de Justicia" (p. 746). Además, planteó que "esa división podría acarrear una interpretación contradictoria de las normas legales y constitucionales con la consiguiente inseguridad jurídica” (p. 746).

En una interesante entrada en su blog "Saber Derecho", Gustavo Arballo (2014) también criticó la idea de dividir a la Corte en salas. Para ello, se basó en tres razones: una conceptual, una institucional y una constitucional. En cuanto a la razón conceptual, afirmó que:

La Corte es (debería ser) el tribunal de la Constitución, no un tribunal de cuarta instancia a propósito de una materia o zona del derecho. En verdad, la Corte no debe fallar sobre "derecho penal" o "derecho civil", sino sólo sobre temas y derechos constitucionales strictu sensu. Dividirla en salas temáticas corrompe ese principio y estimularía a que trate lo que no debe tratar: temas de derecho común. Sería fomentar, y no disuadir, esa idea de la Corte como un "almacén de ramos generales". (párr. 4-5)

En relación con la razón institucional, argumentó que

institucionalmente se pierde la voz de una Corte única, que ve fragmentada su competencia en compartimentos estancos. Se reduce a la "sala" la unidad de decisión perdiendo la diversidad y pluralidad de un tribunal integrado y único. $\mathrm{Y}$ se genera el potencial para habilitar patrones incongruentes de interpretación constitucional si las "salas" adoptan filosofías distintas. Además, aceptar la división en salas es institucionalmente muy peligroso porque se presta para manipulaciones. Nótese que un gobierno podría -en una ley procesal, que puede sancionar por mayoría simple- agrupar todos los jueces que le molestan y asignarlos a una sala a la que le atribuya competencia marginal, y dejar jueces más favorables en una sala temática a la que le asigne centralidad y mayor chance de intervención. (Arballo, 2014, párr. 8-9)

Finalmente, expuso la razón constitucional en estos términos: "Simplemen- 
te, la Constitución Nacional habla de UNA Corte y no contempla, como la de varias provincias, la posibilidad de división en salas" (Arballo, 2014, párr. 10).

Por último, Florencia Ratti e Ignacio Díaz Solimine (2020) también se pronuncian en contra a partir de un análisis exhaustivo de los numerosos conflictos prácticos que generaría dividir a la Corte en salas, aunque excluyen expresamente de su enfoque la eventual compatibilidad o no de esa división bajo nuestro sistema constitucional.

\subsection{Opiniones a favor}

No son muchas las voces doctrinarias que se han pronunciado en trabajos académicos a favor de la división en salas. Además, los pocos que lo han hecho no han desarrollado en profundidad sus argumentos a favor de este tipo de propuestas. A continuación, reseño las más destacadas.

Una de las pocas voces doctrinarias a favor de la división en salas es la de Sagüés (2017), quien afirma que

el tema da lugar a distintos enfoques. La división en salas se justifica por razones de especialización, y siempre que el cúmulo de tareas de la Corte sea muy gravoso. Ello permitiría, en principio, mayor calidad y expeditividad en los fallos. La posibilidad de sentencias contradictorias entre las salas puede resolverse mediante adecuadas convocatorias a tribunal pleno. Todo ello hace que la aludida división no prive de jerarquía al tribunal, sino todo lo contrario. Prestigiosos tribunales supremos europeos y americanos operan de este modo, con éxito y reputación. Al contrario, si la Corte tuviese trabajo reducido (merced al writ of certiorari, o atribución de no atender asuntos carentes de trascendencia), la división en salas pierde necesidad. (p. 414) ${ }^{49}$

\section{Además, plantea que}

normativamente, la Constitución no prohíbe ni promueve la división en salas. Es cierto que el art. 108 habla de "una Corte Suprema", pero la asignación de causas en varias salas no afecta la unidad del cuerpo, que podría actuar en su conjunto ("en pleno") cuando lo decidiese, y de modo obligatorio sobre inconstitucionalidad de normas. Por lo demás, en la experiencia argentina hay muchos cuerpos judiciales que actúan en salas, pese a componer "una" cámara de apelaciones. (Sagués, 2017, pp. 414-415)

49 Énfasis en el original.

50 Énfasis en el original. 


\section{Finalmente, el constitucionalista santafesino concede que}

un fuerte argumento en oposición al régimen divisorio es que, de constituirse en salas de tres miembros, bastarían dos votos para definir puntos fundamentales sometidos a la Corte. Sin embargo, el reglamento podría atender este problema exigiendo tres votos coincidentes; y de no lograr esto, integrar la sala con otro u otros jueces más. (Sagués, 2017, p. 415)

Otra opinión favorable es la de Ekmekdjian (2016, p. 203), quien se limita a afirmar, sin argumento alguno, que coincide con Sagüés y que la división en salas no es inconstitucional.

Miguel Ángel Berçaitz (1988), expresidente de la Corte Suprema entre 1973 y 1976, propuso elevar a nueve la cantidad de jueces y dividirla en
cuatro salas establecidas por ley, con dos jueces cada una: 1) laboral; 2) penal y procesal; 3) administrativo y fiscal; 4) civil y comercial y otras. Tal división debe conservarse o modificarse según resulte de las estadísticas actuales que lleva la Corte. Cada sala se integra con el presidente de la Corte en caso de disidencia entre los dos jueces que la componen”. (p. 860) $)^{51}$

Berçaitz no fundamentó su postura, sino que se limitó a exponerla de forma dogmática.

Finalmente, sin detenerse tampoco a profundizar su propuesta desde la perspectiva constitucional, Pablo Ramella (2008) planteó que:

Creo que en esta materia no hay que tener preconceptos. Si el atiborramiento de las causas aconsejara crear una Corte Suprema con más miembros, dividiéndose en salas, habría que hacerlo porque si constituye un escándalo jurídico, como se ha dicho, la discrepancia en la jurisprudencia, que puede obviarse con el tribunal plenario, como ocurre en México (art. 107, XIII de la Constitución), mayor lo es la demora sin término en la solución de los juicios que constituye en el hecho una verdadera denegación de justicia. Claro que de mantenerse el tribunal único son suficientes cinco miembros, pues de ser más a lo único que llevaría es al retardo de la solución de las causas. (pp. 129-130)

51 Berçaitz (1988) proponía también el control de constitucionalidad de oficio y el efecto erga omnes de las declaraciones de inconstitucionalidad. 


\section{Análisis crítico}

Del repaso de los antecedentes históricos recopilados y de las posturas doctrinarias a favor de la división de la Corte en salas, se podrían agrupar los principales fundamentos esgrimidos para su justificación en cinco categorías:

1. El rechazo a la instancia única en los casos de competencia originaria. Así ocurre con la propuesta de la Constitución de 1826 y la del diputado Emiliano García en 1858.

2. El rechazo al federalismo. Esa fundamentación aparece en el caso de la propuesta del diputado Argañaraz en 1901, que pretende convertir a la Corte Suprema en un Tribunal de Casación de todo el derecho común. De forma similar, las propuestas tanto del Gobierno de facto de Uriburu como la de Carlos Ibarguren, que rechazan también el federalismo, aunque por otras razones: ambas propuestas están influidas en parte por las tendencias centralizadoras del fascismo. ${ }^{52}$

3. Una visión dominada por un supuesto pragmatismo. Esa es la fundamentación principal detrás de la Ley 15271, del proyecto del presidente Illia en 1964 y de la postura de Ramella. Así, la división en salas sería la solución ideal para atender la sobrecarga de trabajo de la Corte Suprema.

4. Una lectura peculiar de los silencios de la Constitución Nacional, que deriva en una autorización de la inexistencia de una prohibición concreta para esa división.

5. La existencia de tribunales divididos en salas en el derecho comparado. Es uno de los argumentos que se exponen reiteradamente, apelando al ejemplo de tribunales europeos o de otros países americanos.

Ninguna de estas fundamentaciones parece sólida o convincente. El rechazo a la instancia única en los casos de competencia originaria previstos en la Constitución desconoce el sistema ideado en los Estados Unidos. ${ }^{53}$ Sin embargo, ese es el modelo que nuestra Constitución adoptó para fijar la atribución de competencia originaria y exclusiva a la Corte Suprema en el artículo 117 de la Constitución. Este sistema de doble instancia y división en salas se planteó solamente en la Constitución de 1826, la que no tuvo aplicación práctica alguna, y en solitario por el diputado García en un debate legislativo en 1858, en el que fue rechazado. Contradice, obviamente, lo previsto en la Constitución.

52 Cfr., entre otros, Mussolini (1941, pp. 160 y ss.).

53 Al respecto, ver Hart y Weschler (1953, pp. 218 y ss.). 
El rechazo al federalismo contradice directamente los artículos 1, 75, inciso 12 y 116 de la Constitución Nacional. Este intento de justificación solo fue expuesto en 1901, en el que fue descartado, y en 1931 y 1948, en sendos proyectos de reformas constitucionales que no tuvieron efecto alguno y que respondían a modelos autoritarios y centralistas en boga en esa época.

La visión pragmática o funcional tiene el antecedente tanto de la Acordada del 25 de agosto de 1958 como de la sanción de la Ley 15271. Se trataría, entonces, de un precedente importante. Sin embargo, es un antecedente que tiene un peso más aparente que real. Más allá de la ausencia de un debate serio sobre el tema en la Cámara de Diputados, y especialmente en la de Senadores, no deja de llamar la atención que tanto el Poder Ejecutivo como el Congreso y la Corte en esa época trataran la división en salas como un método urgente y necesario para lidiar con la sobrecarga de tareas del tribunal. A pesar de ello, lo único que se puso en marcha fue la ampliación de los miembros de la Corte de cinco a siete. Consumada esa ampliación, olvidando que lo había pedido expresamente, la Corte llamativamente ignoró la posibilidad de dividirse en salas. Se trata de un claro acto de irresponsabilidad institucional.

Para tratar de entender esa omisión, no puede olvidarse la actuación preponderante del entonces presidente de la Corte Suprema, Alfredo Orgaz, principal impulsor de este cambio. Fue él quien propuso al Poder Ejecutivo que se estudiara esta reforma. Sin embargo, consumada la ampliación, el presidente Frondizi no siguió la sugerencia de Orgaz de designar a Esteban Imaz para cubrir una de las nuevas vacantes. Ese desaire provocó la renuncia de Orgaz. ${ }^{54} \mathrm{No}$ es aventurado pensar que, luego de la salida del principal inspirador de esa reforma, la Corte perdió todo interés sobre el tema, como lo demuestra el cambio rotundo de opinión al ser nuevamente consultada en 1964. De otra forma, no se explica para qué se pidió una "reforma sustancial", considerada como una solución "de toda necesidad y urgencia" para, después de aprobada, no hacer siquiera el intento de ponerla en práctica. Idéntica consideración merecen las contradicciones evidentes que existen entra la Acordada de 1958 y la nota presentada por la Corte al Senado en $1964 .{ }^{55}$ En cualquier caso, para ser válida, la solución empleada tiene que ajustarse a lo que establece la Constitución, cosa que, como explicaré a continuación, no ocurre en este caso.

La idea de dividir a la Corte Suprema en salas responde a una visión errada

54 Un detallado relato de este proceso puede encontrarse en Oyhanarte (2013, pp. 674 y ss.).

55 Como contrapartida, resalta la coherencia de Aráoz de Lamadrid que votó en disidencia en 1958 y, ya como presidente del Tribunal, redactó la nota presentada por la Corte al Senado en 1964. 
de nuestro sistema constitucional. Es indiscutible que la Corte es el único tribunal creado por la Constitución, que establece en su artículo 108 que el poder judicial será ejercido por "una Corte Suprema de Justicia”. Este artículo fue copiado del Artículo III, Sección 1a de la Constitución de los Estados Unidos de $1787 .{ }^{56}$ Siendo en ese momento senador por el estado de Nueva York, Gouverneur Morris, uno de los redactores de la Constitución de Filadelfia, aclaró que "la Constitución dice que el poder judicial será investido en una suprema corte, y en tribunales inferiores. La legislatura entonces solo puede organizar una suprema corte, pero puede establecer la cantidad de tribunales inferiores que estime pertinente" (Debates in the Congress..., 1802, p. 104). ${ }^{57}$ El alcance de la expresión "una Suprema Corte" ha sido entendido en los Estados Unidos como una suprema corte "indivisible". ${ }^{58}$ De ahí que las propuestas de dividir a la Suprema Corte en salas hayan sido rechazadas en los Estados Unidos en las pocas oportunidades en las que fueron siquiera intentadas en el Congreso. ${ }^{59}$

Es evidente que la unidad a la que se refiere el artículo 108 de la Constitución se rompería a través de la división del tribunal en salas. Tal como se explica en el Considerando $6^{\circ}$ de la Acordada 44/89 de la Corte Suprema, en sentido diametralmente opuesto a su anterior de 1958,

56 Cfr. Seco Villalba (1943, p. 221).

57 "The constitution says, the judicial power shall be vested in one supreme court, and in inferior courts. The legislature can therefore only organize one supreme court, but they may establish as many inferior courts as they shall think proper" (sesión del 14 de enero de 1802, Debates in the Congress..., 1802, p. 104). Cabe aclarar que Morris había representado al estado de Pensilvania en la Convención de Filadelfia de 1787. Sin embargo, en 1800 fue electo senador por el estado de Nueva York, cargo en el que se mantuvo hasta 1803.

58 Así lo demuestra Davies (2006, pp. 684 y ss.). Modernamente, solo he podido encontrar una propuesta académica de división de la Suprema Corte estadounidense en salas en Guthrie y George (2008, p. 1825). Sin embargo, los autores no analizan el alcance del Artículo III, Sección 1a de la Constitución de Filadelfia, sino que se limitan a asumir que la división en paneles es constitucional (Guthrie y George, 2008, p. 1847, nota al pie 85). Se trata de una posición ciertamente peculiar que no he visto considerada seriamente por ningún otro autor estadounidense. Sin embargo, al momento de mandar este trabajo para su publicación, tomé conocimiento de un artículo que será publicado el año que viene y en el que también se propone un mecanismo similar, aunque se expresan dudas en materia constitucional (Doerfler y Moyn, 2021, p. 52). En el marco de la polémica generada en algunos sectores luego de las designaciones del presidente Donald Trump de los Justices Neil Gorsuch, Brett Kavanaugh y Amy Coney Barrett, es probable que haya más voces del sector académico que propongan reformas a la Suprema Corte en líneas similares.

59 En ocasión de discutirse la propuesta de reorganización judicial impulsada por Franklin Delano Roosevelt, Jr. conocida como el court-packing plan, el Chief Justice Charles Evans Hugues envió una carta al senador Burton K. Wheeler, que fue leída el 29 de marzo de 1937 en el Senado. Allí, luego de recordar el artículo III, sección 1a de la Constitución de 1787, el Chief Justice sostuvo que la Constitución no parece autorizar dos o más Cortes o dos o más partes separadas de la Corte funcionado efectivamente como tribunales separados (Congressional Record..., 1937, p. 2815). En idéntico sentido, años después, el Justice William Brennan sostuvo que el hecho de que 
resulta fundamental destacar que, por cuanto es imperativo constitucional que esta Corte sea "una" (art. [108]), el estudio y decisión de los procesos que atañen a su ministerio no puede estar asignado o limitado a sólo alguno de sus miembros. Ahora bien, síguense de ello dos consecuencias a cual más importante. La primera, que si el Tribunal debe actuar por la Constitución como una unidad, el aumento de sus componentes carece de todo influjo en la magnitud del ingreso de las causas a decidir. La restante, que, en tales condiciones, ese igual número de litigios deberá ser estudiado no por cinco sino por nueve jueces. Ambas conclusiones, obviamente, son demostrativas de que la suma de miembros para un órgano unitario no es un vehículo conducente para variar el ingreso de expedientes; ni para aliviar lo que constituye el quehacer primordial de los magistrados: resolver litigios; ni para agilizar el curso de los procesos. ${ }^{60}$

Si bien el foco de estas reflexiones está relacionado con la hipótesis del aumento de jueces de la Corte, sus argumentos son plenamente aplicables a la afectación de la unidad del tribunal que se produciría a través de su división en salas. De hecho, Rosatti (2017, p. 446) opina que la Acordada 44/89 invalidó la habilitación de la división de la Corte en salas dispuesta a través de la Ley $15271 .{ }^{61}$

En realidad, quienes afirman que no se rompe la unidad a través de su división en salas pretenden demostrar la cuadratura del círculo: si tengo un único tribunal con una función especial y lo divido en dos o más salas, esa unidad se pierde irremediablemente. Esa objeción no se salva previendo excepciones parciales para el tratamiento de ese único tribunal en pleno para ciertos casos. ${ }^{62}$ Olvidan, además, que la forma sigue a la sustancia y no al revés. Esto, que es obvio, no se aborda directamente, sino que simplemente se rechaza el argumento sin mayor análisis. Pero, aunque parezca una perogrullada, si divido uno por cualquier otro número natural, el resultado indefectiblemente es menor a uno. Podría argumentarse que la mayoría de las cámaras de apelación del fuero federal se dividen en salas y, sin embargo, nadie objeta que esa división es

la Constitución asigne el poder judicial a solo una Suprema Corte impide que ese tribunal tome decisiones por comités, paneles o secciones (Brennan, 1960, p. 406).

60 Corte Suprema de Justicia de la Nación. Pronunciamiento sobre proyecto de ley modificatorio de la composición del Tribunal, Fallos: 312:1513, p. 1515 (1989).

61 Esta opinión es compartida por Badeni y Ekmekdjian, quienes plantean que la Acordada 44/89 declaró inconstitucional la Ley 15271 en cuanto autoriza la división en salas. Cfr. Badeni (2010, p. 746) y Ekmekdjian (2016, p. 203).

62 Obviamente, sin ese supuesto, la propuesta de dividir a la Corte en salas suma más problemas: "Pensemos qué valor puede tener la decisión de un tribunal una de cuyas salas declara inconstitucional a la ley y la otra no. ¿Cuál es la doctrina definitiva? ¿Cuál es la opinión de la Corte? No lo sabemos” (Bianchi, 1988, p. 975). 
inconstitucional. Sin embargo, esa objeción perdería de vista un hecho fundamental: así como la Constitución crea de forma expresa "una Corte Suprema de Justicia" en su artículo 108, también le reconoce expresamente al Congreso la atribución de establecer "los demás tribunales inferiores" en el territorio de la Nación. Dicho de otro modo, el margen de acción del Congreso para establecer y dividir "los demás tribunales inferiores" no existe en el caso de la Corte Suprema: se trata, insisto, del único tribunal que la propia Constitución establece. A pesar de conocer y considerar antecedentes como la Constitución de Cádiz de 1812 o, mucho más importante, la Constitución de 1826, el constituyente no siguió esos ejemplos. De hecho, los descartó y no autorizó ni previó la división en salas. ${ }^{63}$ Además, de forma diametralmente opuesta a lo que ocurre con la Corte Suprema, la división en salas de las cámaras de apelación no viola norma constitucional alguna ni modifica la sustancia de esos tribunales inferiores.

Quienes rechazan este argumento sostienen que se basa en una interpretación meramente literal del artículo 108 de la Constitución. Sin embargo, ese cuestionamiento está lejos de ser suficiente. Si ese fuera el caso, no habría mucho que objetar. Más allá de las limitaciones que se considere que puede tener el método de interpretación literal o textualista, lo cierto es que la primera fuente de interpretación de cualquier texto legal es su letra. Y si la letra es clara, no cabe apartarse de ella: A verbis legis non est recedendum. ${ }^{64}$ Pero ese no es el punto principal. El punto pasa por destacar que una interpretación que pretenda desconocer la letra de una norma clara tiene que estar debidamente justificada. No alcanza con impugnar una interpretación por el solo hecho de que se ajuste "literalmente" al texto constitucional. Se requiere un esfuerzo mucho mayor: por ejemplo, demostrar que respetar ese texto a rajatabla podría llevar a resultados absurdos, ${ }^{65} \mathrm{o}$, en su defecto, que esa interpretación frustra la función original, la intención o el "espíritu" de la norma. ${ }^{66}$

Nada de eso ocurre en este caso. ¿Se llega a algún resultado absurdo por interpretar que cuando el artículo 108 de la Constitución se refiere a "una Corte Suprema de Justicia” no se la pueda dividir en salas? Obviamente no. La Corte Suprema ha funcionado así desde su instalación y así lo entendieron los constituyentes que participaron, ya sea como ministros o legisladores en la re-

63 Sobre la influencia de la Constitución de 1826 y la Constitución de Cádiz de 1812 en la Constitución Nacional, ver García-Mansilla y Ramírez Calvo (2006, pp. 72-80 y pp. 107-137).

64 Cfr. Scalia y Garner (2012, pp. 56 y ss.).

65 Cfr. Scalia y Garner (2012, pp. 234 y ss.).

66 Cfr. Wurman (2017, pp. 18-19). 
dacción y consideración de los distintos proyectos de organización de la justicia federal y como jueces de la propia Corte. A pesar de ello, se pretende que esa interpretación no es aceptable por el solo hecho de que, en realidad, impide la propuesta interesada del intérprete.

Quienes proponen la división en salas omiten analizar cuál es el impacto que tiene la modificación de un tribunal que fue concebido para una función especial como es el caso de la Corte Suprema. Cualquier modificación en la estructura de la Corte tiene el potencial de alterar su función y también la de modificar la percepción de esa función por parte de abogados, litigantes, los propios jueces de la Corte e incluso de la población en general. Y no podría ser de otra forma, ya que no existe una estructura neutral para la Corte Suprema. Las diferentes estructuras que muestran los tribunales constitucionales en el mundo son un reflejo, precisamente, de las diferentes concepciones que se tienen acerca del rol que esos tribunales tienen en el sistema. ${ }^{67}$

Los partidarios de la división en salas también omiten considerar que no se concilia con otros artículos de la Constitución y no únicamente el artículo 108. Contradice, por ejemplo, el artículo 113 de la Constitución en cuanto establece que "[l]a Corte Suprema dictará su reglamento interior". Además de violar de forma idéntica el criterio de singularidad establecido por el artículo determinado "la", lo cierto es que del texto constitucional se deduce que la organización interna de la Corte solo puede ser regulada por ella misma a través del dictado de su "reglamento interior". Esa facultad es análoga a la prevista en el artículo 66 que establece que cada Cámara del Congreso dictará su reglamento. ${ }^{68}$ En consecuencia, aun cuando se considere que es deseable la división en salas y se pretenda que las referencias a "una Corte" -en el artículo 108- o a "la" Corte Suprema -en el artículo 113- no son relevantes, lo cierto es que el Congreso no podría disponerla. Una lectura armónica de la Constitución obliga a concluir forzosamente que el Congreso no tiene esas facultades. En caso de que existieran, fueron asignadas por la Constitución a la propia Corte Suprema.

Frente a este planteo, podría argumentarse que el Congreso tiene efectivamente atribuciones para regular ciertos aspectos de la jurisdicción de la Corte y que, a través de esa facultad, podría disponerse la división en salas. Pero sería

67 Para profundizar el planteo, ver Robinson (2013, pp. 173 y ss.).

68 Montes de Oca (1896) explica que a través de este artículo se le acuerda a la Corte Suprema "el privilegio de dictar sus reglamentos, obedeciendo a consideraciones análogas a las que se han tenido en cuenta para dejar a cada cámara del congreso la prerrogativa de dictarse su reglamento especial" (p. 528). 
un grave error conceptual: lo cierto es que la atribución del Congreso prevista en el artículo 117 de la Constitución de prescribir las reglas y excepciones de la jurisdicción apelada de la Corte Suprema no incluye ni se refiere a la estructura, organización o funcionamiento interno del tribunal, tampoco a la forma en la que esa jurisdicción será ejercida. Sostener lo contrario sería confundir el otorgamiento de la jurisdicción a un tribunal con el intento de regular la forma en la que los jueces ejercerán esa jurisdicción otorgada por la Constitución. Es decir, con la forma en la que los jueces ejercerán su principal atribución: ejercer el poder judicial (la "función judicial") a la que se refiere el artículo 108 de la Constitución. Y, obviamente, no es lo mismo. ${ }^{69}$ La división en salas es una forma subrepticia de regular tanto la estructura, la organización y el funcionamiento interno del tribunal como la forma del ejercicio del propio poder judicial (o "función judicial") que la Constitución le otorga a la Corte Suprema. Pero el Congreso no puede hacerlo, ya que estaría violando el principio de la separación de los poderes.

Podría intentar replicarse que si el Congreso tiene la atribución de determinar la cantidad de jueces de la Corte Suprema podría también tener la de ordenar su división en salas. Sin embargo, esa atribución de determinar la cantidad de jueces de la Corte Suprema no surge como tal expresamente del texto constitucional. Surge, de forma implícita, del artículo 75, inciso 20 de la Constitución en cuanto establece que corresponde al Congreso "crear y suprimir empleos". 70 Es evidente que esa facultad se limita a lo que dice: crear y suprimir empleos y no a regular la estructura, la organización, el funcionamiento interno o la forma en la que la Corte va a ejercer el "poder judicial" (o "función judicial").

Quienes no aceptan este tipo de interpretación armónica y sistemática del texto constitucional, apelan a un último argumento: la Constitución no prohíbe expresamente esa división en salas. Se trata de un espejismo constitucional que pretende encontrar fundamento en los silencios de la Constitución. A través de una lectura ciertamente peculiar de esos silencios, se pretende derivar una autorización para hacer algo que no está prohibido expresamente. Al respecto, coincido con Arballo (2014) cuando plantea que

hay un modo de interpretación constitucional, muy de penalistas, que es el de creer que el legislador puede hacer cualquier cosa que la CN no prohíba. Pero eso

69 Cfr. Whilloughby (1929, Tomo I, pp. 40-41 y Tomo III, pp. 1623-1624).

70 Conforme lo previsto en el artículo 110 de la Constitución, el cargo de juez de la Corte Suprema es un "empleo". 
no funciona así. El legislador sólo puede hacer lo que la CN le permite. Y no habilita la división en Salas. Pensar en una Corte dividida en Salas es como pensar en un Congreso dividido en "subcámaras", todas ellas con potestad de sancionar leyes. Del mismo modo que un diputado tiene derecho a votar en todas las leyes (y sería un escándalo que solo le dejaran votar en leyes de ciertos temas) un juez de la Corte -tal como está escrita la CN [Constitución Nacional]- tiene derecho a votar en todos los casos. (párr. 11) ${ }^{71}$

La Corte Suprema ha sostenido un criterio similar de forma constante a lo largo de su historia. En 1887, en el caso Sojo, afirmó que

el mandatario solo puede hacer aquello a que se halla expresa o implícitamente autorizado por su mandato, y este principio es el mismo que sirve de base a la interpretación de los poderes en el orden constitucional. Solo a las personas en el orden privado es aplicable el principio de que nadie puede ser obligado a hacer lo que la ley no mande, ni privado de hacer lo que la ley no prohíbe; pero a los poderes públicos no se les puede reconocer la facultad de hacer lo que la Constitución no les prohíbe expresamente, sin invertir los roles respectivos de mandante y mandatario y atribuirles poderes ilimitados. ${ }^{72}$

En idéntico sentido, en 2013, en el caso Rizzo, el Alto Tribunal explicó que ningún poder puede arrogarse mayores facultades que las que le hayan sido conferidas expresamente [...]. La regla según la cual es inválido privar a alguien de lo que la ley no prohíbe, ha sido consagrada en beneficio de los particulares (artículo 19 de la Constitución Nacional), no de los poderes públicos. Estos, para actuar legítimamente, requieren de una norma de habilitación. ${ }^{73}$

En consecuencia, es una regla indiscutible que todos los poderes del Gobierno federal están sujetos al principio de que solamente pueden ejercer facultades que les hayan sido conferidas por la Constitución. Evidentemente, no es el caso de la división de la Corte Suprema en salas por decisión del Congreso: esa facultad no surge ni de forma expresa, ni de forma implícita ni puede derivarse de una lectura razonable y sistemática de nuestra Constitución.

La apelación a una fuente externa como el derecho comparado tampoco

71 Énfasis en el original.

72 D. Eduardo Sojo, por recurso de Habeas Corpus, contra una resolución de la H. Cámara de Diputados de la Nación, Fallos: 32:120, p. 135 (1887).

73 Rizzo, Fallos 336:760, considerando $7^{\circ}$, p. 782 (2013). 
sostiene la postura de quienes fomentan la división en salas. Nuestra Corte Suprema no es un tribunal de casación de estilo europeo, por el contrario, es un tribunal que fue calcado de su modelo estadounidense. ${ }^{74} \mathrm{~A}$ la hora de acudir al derecho comparado, es fundamental tener en cuenta tanto los elementos determinantes como los elementos secundarios o "fungibles" de un sistema jurídico. El reconocimiento de esos elementos determinantes de un sistema permite extraer conclusiones válidas de la utilización del método comparativo. A través de esa distinción, el recurso al derecho extranjero como fuente de interpretación puede ser realizado válidamente, evitando la microcomparación, que no presta debida atención y soslaya las diferencias ideológicas y teleológicas entre los distintos ordenamientos jurídicos. ${ }^{75}$

Esta técnica para la utilización del derecho comparado impide utilizar erróneamente modelos extranjeros con elementos determinantes distintos de los del ordenamiento local y, por lo tanto, inaplicables en el contexto del derecho nacional. Una comparación útil es posible solamente si las instituciones legales extranjeras a las cuales se recurre cumplen una función similar a la que tienen en el ordenamiento jurídico local. De lo contrario, la utilización del derecho extranjero llevará a conclusiones falsas o inaplicables en nuestro país. Sin embargo, esta realidad tan evidente ha sido obviada en este caso, en especial en aquellos que recurrieron a modelos extranjeros que nada tienen que ver con nuestro sistema constitucional como un intento de armar un soporte argumental en favor de la propuesta de división en salas. Por ello, es que el análisis en esos casos pudo llegar a asimilar desacertadamente, y sin más que por elementos secundarios (fungibles), a sistemas jurídicos que intrínsecamente no se corresponden entre sí. ${ }^{76}$

Estas advertencias no fueron tenidas en cuenta por quienes defendieron la división de la Corte en salas apelando al derecho comparado. Basta ver, por ejemplo, que el diputado Manuel Argañaraz puso como ejemplo a Francia, y que a la hora de elaborar la Ley 15271 se tomaron como antecedentes del

$74 \mathrm{Al}$ respecto, son terminantes las referencias durante el debate de la Ley 182 de la Confederación por parte de exconvencionales constituyentes de 1853, como Martín Zapata (sesión del 18 de agosto de 1857, Diarios de Sesiones..., 1857, pp. 221-224), Juan del Campillo (sesión del 12 de julio de 1858, Congreso Nacional. Actas de las sesiones..., 1891, p. 512), Facundo Zuviría (sesión del 12 de julio de 1858, Congreso Nacional. Actas de las sesiones..., 1891, p. 519) y Juan María Gutiérrez (sesión del 14 de julio de 1858, Congreso Nacional. Actas de las sesiones..., 1891, p. 522).

75 En este punto, sigo las enseñanzas de Constantinesco (1971, pp. 263-270).

76 También se suele incurrir en el vicio opuesto: anotar solo las diferencias exteriores, no obstante la coincidencia absoluta que existe en los puntos nodales (elementos determinantes) de la estructura 
derecho comparado a países como Colombia, Costa Rica, Venezuela y México. Ninguno de esos países tiene un diseño del Poder Judicial compatible con el nuestro. Algo similar, aunque exacerbado, ocurre con quienes simplemente apelaron a la existencia de "prestigiosos tribunales supremos europeos y americanos [que] operan de este modo, con éxito y reputación” (Sagüés, 2017, p. 414) para justificar la constitucionalidad de la división en salas. Ni el éxito ni la reputación de esos tribunales son excusas válidas para imitarlos sin más, dejando de lado las claras diferencias determinantes y estructurales de diseño y evolución constitucional en cada caso. ${ }^{77}$

Más allá de la evidente falta de similitud con nuestro sistema constitucional, existe otro aspecto fundamental ignorado por quienes defendieron la división en salas apelando a ejemplos del derecho comparado: los países citados como fundamento de ese tipo de propuestas tenían cortes divididas en salas porque así lo disponía expresamente el texto de sus constituciones. Así ocurrió en el caso de la Ley 15271. A modo de ejemplo, la Constitución de Colombia de 1886 previó la división en salas de su Corte Suprema a partir de la reforma introducida por el acto legislativo $\mathrm{N}^{\circ} 3$ del 31 de octubre de 1910, que en su artículo 35 establecía: "La Corte Suprema de Justicia se compondrá de nueve Magistrados. La ley la dividirá en Salas, señalará a cada una de ellas los asuntos de que debe conocer separadamente, y determinará aquellos en que deba intervenir toda la Corte" (Segovia, 1914, p. 209). El propósito declarado de la reforma era sentar las bases "para la organización de la Corte Suprema Justicia como Tribunal ordinario y Tribunal de casación". ${ }^{78}$

Algo similar ocurre con el caso de Costa Rica. A instancias del proyecto de nueva constitución impulsado por la Junta de la Segunda República, el Poder Judicial sufrió modificaciones importantes que fueron reflejadas en la Constitución de $1949 .{ }^{79}$ El artículo 157 de la nueva constitución de Costa Rica dispuso que "[1]a Corte Suprema de Justicia estará formada por diecisiete Magistrados elegidos por la Asamblea Legislativa, la cual integrará las diversas Salas que indique la ley" (Sáenz Carbonell y Masís Pinto, 2006, p. 267).

En Venezuela, la Constitución de 1961 establecía en su artículo 212 que: "La Corte Suprema de Justicia funcionará en Salas, cuya integración y competencia será determinada por la ley. Cada Sala tendrá, por lo menos, cinco Magistrados" (Ayala

filosófica e ideológica de los sistemas en estudio. Cfr. Andruet (1996, p. 1137).

77 Esas diferencias han sido expuestas en detalle en Nogueirá Alcalá (2005, pp. 84-167).

78 Cfr. Segovia (1914, p. 36).

79 Al respecto, ver Sáenz Carbonell y Masís Pinto (2006, pp. 259-265). 
Corao, 1997, pp. 385 y ss.). A su vez, en México, la Constitución prevé expresamente la división de su corte en salas desde la reforma constitucional de $1928 .{ }^{80}$

Desconozco las razones por las que semejantes diferencias no fueron siquiera consideradas por quienes citaron esos antecedentes, dado que nunca fueron explicitadas, especialmente al momento de sancionarse la Ley 15271. Sin embargo, es evidente que se trata de un aspecto central e insoslayable que debió haber sido abordado. Es más, podría argumentarse a partir de esos mismos ejemplos que la adopción de la división en salas requeriría, al igual que esos países, de una disposición constitucional expresa que la autorizara o dispusiera concretamente. En consecuencia, la apelación a los casos de Colombia, Costa Rica, Venezuela y México demostraría que para poder impulsar la división en salas de la Corte Suprema en nuestro país, sería necesaria una reforma constitucional a través del mecanismo previsto en el artículo 30 de la Constitución Nacional.

Finalmente, quienes proponen una división en salas "temáticas" para organizar el funcionamiento de la Corte en una sala civil, una penal, etc. soslayan dos obstáculos constitucionales que demuestran en forma contundente la inconstitucionalidad de la propuesta. Los artículos 116 y 117 de la Constitución Nacional establecen la competencia de la Corte Suprema. Por un lado, determinan de manera taxativa cuál es la competencia originaria de toda la Corte. Limitar el ejercicio de esa competencia a una sala del Tribunal implica un apartamiento claro y evidente de la letra clara de la Constitución. La competencia originaria tiene origen constitucional y no puede ser modificada por el Congreso en ningún caso. Adviértase que en ejercicio de esa competencia, la Corte Suprema decide casos en los que no se debaten cuestiones constitucionales. Su intervención en instancia única está motivada por las partes intervinientes.

Esta objeción no se salva disponiendo que la Corte Suprema funcione en pleno en los casos en los que tiene que ejercer la competencia originaria. La razón, una vez más, es evidente: nuestra Constitución también le atribuye la competencia por apelación a toda la Corte Suprema y no a una parte de esta. Que la Constitución haya facultado al Congreso a establecer las reglas y excepciones correspondientes solo implica el poder de determinar en qué casos la Corte Suprema puede ejercer esa jurisdicción. Pero limitar el ejercicio de su competencia jurisdiccional a una porción del Tribunal implica una violación notoria de las atribuciones de la Corte.

A eso se le suma que la división en salas implicaría convertir al Tribunal en

80 Ver https://archivos.juridicas.unam.mx/www/bjv/libros/6/2802/8.pdf. 
una magistratura de casación, en franca violación del federalismo. Concretamente, violaría la reserva prevista en los artículos 75 , inciso $12^{81}$ y $116^{82}$ que disponen que la aplicación e interpretación del derecho común, es decir, de los códigos de fondo, corresponde a la justicia provincial. ${ }^{83}$ Esa es la razón por la que muchos de los tribunales superiores de justicia provinciales están divididos en salas y así lo reconocen sus propias constituciones. Pero la Corte Suprema no es un tribunal de derecho común, mucho menos un tribunal de casación al estilo francés. En consecuencia, a la luz del diseño de nuestro sistema constitucional, no corresponde a la Corte Suprema la unificación de la jurisprudencia en cuestiones de derecho común. Así lo reconoció la propia Corte en Casal:

Que el llamado objetivo político del recurso de casación, sólo en muy limitada medida es compatible con nuestro sistema, pues en forma plena es irrealizable en el paradigma constitucional vigente, dado que no se admite un tribunal federal que unifique la interpretación de las leyes de derecho común y, por ende, hace inevitable la disparidad interpretativa en extensa medida. La más fuerte y fundamental preocupación que revela el texto de nuestra Constitución Nacional es la de cuidar que por sobre la ley ordinaria conserve siempre su imperio la ley constitucional. Sólo secundariamente debe admitirse la unificación interpretativa, en la medida en que la racionalidad republicana haga intolerable la arbitrariedad de lesiones muy groseras a la igualdad o a la corrección de interpretaciones

81 Artículo 75, inciso 12, CN: "Corresponde al Congreso: [...] 12. Dictar los Códigos Civil, Comercial, Penal, de Minería, y del Trabajo y Seguridad Social, en cuerpos unificados o separados, sin que tales códigos alteren las jurisdicciones locales, correspondiendo su aplicación a los tribunales federales o provinciales, según que las cosas o las personas cayeren bajo sus respectivas jurisdicciones; y especialmente leyes generales para toda la Nación sobre naturalización y nacionalidad, con sujeción al principio de nacionalidad natural y por opción en beneficio de la argentina: así como sobre bancarrotas, sobre falsificación de la moneda corriente y documentos públicos del Estado, y las que requiera el establecimiento del juicio por jurados”. El destacado me pertenece.

82 Artículo 116, CN: "Corresponde a la Corte Suprema y a los tribunales inferiores de la Nación, el conocimiento y decisión de todas las causas que versen sobre puntos regidos por la Constitución, y por las leyes de la Nación, con la reserva hecha en el inc. 12 del Artículo 75: y por los tratados con las naciones extranjeras: de las causas concernientes a embajadores, ministros públicos y cónsules extranjeros: de las causas de almirantazgo y jurisdicción marítima: de los asuntos en que la Nación sea parte: de las causas que se susciten entre dos o más provincias; entre una provincia y los vecinos de otra; entre los vecinos de diferentes provincias; y entre una provincia o sus vecinos, contra un Estado o ciudadano extranjero". El destacado me pertenece.

83 Así es que el artículo 15 de la Ley 48 dispone que: "Cuando se entable el recurso de apelación que autoriza el artículo anterior, deberá deducirse la queja con arreglo a lo prescripto en él, de tal modo, que su fundamento aparezca de los autos y tenga una relación directa e inmediata a las cuestiones de validez de los artículos de la Constitución, leyes, Tratados o comisiones en disputa, quedando entendido, que la interpretación o aplicaciones que los tribunales de provincia hicieren de los códigos Civil, Penal, Comercial y de Minería, no dará ocasión a este recurso por el hecho de ser leyes del Congreso, en virtud de lo dispuesto en el inciso 11, artículo 67 [hoy inciso 12 del artículo 75] de la Constitución”. 
carentes de fundamento. Pero resulta claro que no es lo que movió centralmente a los constituyentes a la hora de diagramar el sistema judicial argentino. ${ }^{84}$

Este principio, varias veces olvidado en la práctica por la propia Corte, es un pilar fundamental de nuestra organización constitucional. Spota (2001) sostenía con acierto que "este desarrollo de la dinámica operativa de la vida judicial argentina, va totalmente a contramano del origen y naturaleza del control de constitucionalidad" (p. 21).

En ese mismo sentido, Ramírez Calvo (2010) observa con lucidez que

[1]a facultad del Congreso de la Nación de sancionar los códigos de fondo uniformes para todo el país, no implica alteración de las jurisdicciones provinciales. [...] La correcta interpretación, acorde con el sistema de la Constitución, es que se trata de leyes locales sancionadas por el Poder Legislativo Federal. Eso implica que su interpretación corresponde a los tribunales locales, como cualquier otra norma provincial. El error radica en suponer, muy en línea con nuestras convicciones imperiales heredadas de Francia a través de España, que la interpretación de esos códigos debe ser uniforme en todo el país. La Constitución no prevé eso, sino que, por el contrario, admite [...] distintas interpretaciones de acuerdo con cada jurisdicción local. (pp. 473-474)

La división "temática”, además, alentaría a futuro la designación de jueces con perfiles de especialistas en ramas del derecho común. De esta forma, se forzaría indebidamente una mutación del rol de la Corte Suprema, que dejaría de ser cabeza de uno de los tres poderes del Gobierno federal y último intérprete de la Constitución Nacional para convertirse en un tribunal de alzada multifuero, dividido por materias.

Esta última objeción podría sortearse a través de una división a secas, con salas de idéntica competencia. Sin embargo, esa división no despeja el resto de los problemas constitucionales que señalé previamente. Además, como bien señala Arballo (2014), aparece "la posibilidad de que haya criterios distintos en la Corte en temas análogos, generando inseguridad jurídica y obligando a que se dicten 'plenarios', lo que lastra bastante la practicidad supuesta en la división” (párr. 16).

En definitiva, pese a lo atractivo de la sencillez del esquema de segmentación de tareas que se pretende imponer con la división en salas, lo cierto es que la Corte dividida dejaría de ser "la Corte Suprema de Justicia" a la que se refiere nuestra Constitución para transformarla en una simple corte de casación, uni-

84 Matías Eugenio Casal y otro, Fallos: 328:3399, considerando 13º pp. 3430-3431 (2005). Énfasis en el original. 
ficadora de la jurisprudencia. Estaríamos intentando solucionar un problema a costa de desdibujar institucionalmente al Alto Tribunal y, así, el remedio sería peor que la enfermedad. ${ }^{85}$

¿Estas objeciones implican estar obligados a mantener la situación actual de sobrecarga de trabajo en el que la Corte aparece entre dos desfiladeros? ${ }^{86}$ Por supuesto que no. Podríamos ver, por ejemplo, qué se hizo en el país cuyas instituciones tomamos como modelo. Tal como sostuvo Félix Frankfurter (1939), la idea de aumentar el número de jueces de la Suprema Corte o dividirla en salas se propuso en algunas oportunidades a fines del siglo XIX en los Estados Unidos, también sin éxito:

De forma recurrente se instaron variantes de la propuesta de aumentar el número de miembros de la Corte para hacer frente al aumento de sus actividades después de la Guerra Civil. Así, se propuso un mayor número de miembros de la Corte, en un rango de quince a veinticuatro, a fin de permitir turnos en las sesiones de la Corte o trabajar por divisiones permanentes. Los casos de Inglaterra y Francia fueron citados como ejemplos de tales esquemas de organización judicial, y algunos de los estados de los Estados Unidos han aprovechado su experiencia. Pero cualquiera de estos dispositivos sería fatal para las funciones especiales de la Corte Suprema. Un cambio de integrantes de forma contemporánea acentuaría desastrosamente el factor personal en las sentencias constitucionales, y las salas judiciales dentro de la Corte Suprema requerirían un mecanismo para ajustar los conflictos entre esas salas. Felizmente, estos dispositivos nunca llegaron a ser implementados. Pero su propuesta persistente retrasó el único remedio eficaz. No fue sino hasta 1891 que el Congreso aprobó la legislación necesaria. En lugar de aumentar el tamaño de la Corte, se disminuyó su actividad. (pp. 28-29) ${ }^{87}$

\section{Transitar un camino similar para llegar gradualmente a una normativa aná-}

85 Cfr. Rosales Cuello (1993, p. 994).

86 Cfr. Rosatti (2018, p. 986).

87 "Variants of the proposal to increase the membership of the Court for dealing with the increase of its business after the Civil War were recurrently urged. Thus a larger membership of the Court was proposed, ranging from fifteen to twenty-four, so as to permit shifts in the sittings of the Court or work by standing divisions. England and France were cited as examples of such schemes of judicial organization, and their experience has been drawn upon by some of the states of the United States. But either of these devices would be fatal for the special functions of the Supreme Court. A contemporaneously shifting personnel would disastrously accentuate the personal factor in constitutional adjudications, and divisional courts within the Supreme Court would require a mechanism for adjusting conflicts among the divisions. Happily these devices never attained enactment. But their persistent advocacy delayed the only efficacious remedy. Not till 1891 did Congress pass the requisite legislation. Instead of increasing the size of the Court, it decreased its business" (Frankfurter, 1939, pp. 28-29). 
loga a la que regula actualmente la competencia de la Corte Suprema de los Estados Unidos sería mucho más inteligente. ${ }^{88}$ No solo atacaría de raíz el problema de la sobrecarga de trabajo, sino que, además, lo haría respetando el estatus constitucional que le corresponde a la Corte Suprema de Justicia de la Nación como cabeza de uno de los tres poderes del Gobierno federal.

\section{Conclusión}

La división de la Corte Suprema en salas tiene serios obstáculos constitucionales. Además, es una mala idea que no aporta beneficios claros y que tiene el costo altísimo de forzar de forma evidente a la Constitución. Esa división no soluciona el problema de sobrecarga de trabajo de la Corte, como se pretende. Por el contrario, se corre el riesgo de generar una supuesta solución (que no es tal) para los casos menos relevantes y, como contrapartida, profundizar el problema al sumar demoras en los casos más importantes, que tendrán que ser revisados por un mayor número de jueces. ${ }^{89}$

Esta idea no solo es contraria a la Constitución, sino que desnaturaliza el rol constitucional de la Corte Suprema como guardiana de la Constitución. No solo la desvía del foco principal de atender casos trascendentes desde una perspectiva constitucional, sino que la convierte en un tribunal más, en una instancia adicional que dilatará los juicios y a la que todo litigante aspirará a llegar de una u otra forma. Multiplicar la Corte por dos, por tres o por cinco inducirá a más litigantes a tratar de revertir sentencias desfavorables, agravando así el problema que supuestamente se quiere solucionar. ${ }^{90}$ Guste o no, el rol principal de la Corte Suprema no es el de corregir los errores de otros tribunales. ${ }^{91}$

88 Ver, al respecto, entre otros, Frankfurter y Landis (1928, p. 1); Sternberg (2008, p. 1).

89 Para profundizar los problemas e inconvenientes de índole de práctico que se generarían en caso de dividir a la Corte Suprema en salas, sugiero ver el excelente trabajo de Ratti y Díaz Solimine (2020).

90 La Corte Suprema denunció la alteración de su rol institucional como consecuencia de la expansión de casos en el contexto de reclamos previsionales: "no puede negarse la evidencia empírica que demuestra que la vigencia del procedimiento establecido por el art. 19 [de la Ley 24463] en cuestión ha tenido como consecuencia una gran expansión en el ámbito de competencia de la Corte, tanto en el aspecto cuantitativo como en la diversidad de temas fácticos y jurídicos que ha debido abordar, con la consiguiente alteración del rol que venía cumpliendo como intérprete final de la Constitución Nacional para adaptar su funcionamiento, cada vez en mayor medida, al de un tribunal de instancia común” (Mabel Itzcovich v. ANSES, Fallos: 328:566, considerando 8º p. 581, 2005). Tal como sostuvo la Jueza Carmen M. Argibay, "[t]al expansión cuantitativa y cualitativa entorpece y afecta el eficaz cumplimiento de su función de custodio e intérprete último de la Carta Magna, a punto tal que el rol institucional que le ha sido encomendado se ha visto totalmente desdibujado en los últimos años" (Fallos: 328:566, considerando 4º, p. 610).

91 "The function of the Supreme Court is conceived to be, not the remedying of a particular litigant's wrong, but the consideration of cases whose decision involves principles, the application of which 
Desde la perspectiva del federalismo, la división en salas temáticas infringiría la competencia otorgada a la Corte Suprema en los artículos 116 y 117 y la convertiría en un tribunal de casación de derecho común, en violación directa de lo que establece la Constitución Nacional en materia de distribución de jurisdicción y competencias. Eso, que alguna vez estuvo muy claro, hoy parece haberse olvidado en nuestro país. Sin embargo, es indispensable pensar y diseñar cualquier reforma a la Corte Suprema a partir de (y no a pesar de) nuestro diseño constitucional. En lo que se refiere al Poder Judicial federal en general y a la Corte Suprema en particular, seguimos de forma directa el modelo de la Constitución de los Estados Unidos. Por eso, no deja de sorprender que se pase por alto que los sistemas que se citan en apoyo de la división en salas, en especial los europeos y de algunos países americanos, se apartan ostensiblemente de ese modelo. Del mismo modo, llama la atención que se cite el caso de las provincias que tienen tribunales superiores divididos en salas sin reparar en que, bajo nuestro sistema constitucional, su actividad principal es, precisamente, la aplicación del derecho común.

Zavalía (1941) recordaba que en Francia, que ha servido de ejemplo a la mayoría de esos tribunales, "la administración de justicia no es un poder, como en Estados Unidos y la República Argentina, sino una simple rama o dependencia del Poder Ejecutivo" (p. 304, nota al pie 12). ${ }^{92}$ En ese mismo sentido, Spota (1995) afirmaba:

En Europa no hubo, como que no hay todavía hoy realmente poder judicial. El principio de supremacía constitucional es operado por los tribunales constitucionales, que no integran la judicatura. Hay simplemente administración de justicia. [...] Poder judicial existe en aquellas estructuras políticas en las que los jueces tienen la capacidad para declarar la inconstitucionalidad de normas o actos del Poder Ejecutivo y, como consecuencia de ello, marginar la aplicación de unas y de otros. (p. 1366)

También llama la atención que aquellos que proponen hoy este tipo de medidas no reparen en que el Congreso, hace escasos 14 años, decidió reducir a cinco la cantidad de integrantes de la Corte Suprema en 2006 a través de la Ley 26183. Y lo hizo para dar una señal, poner un punto de inflexión y volver al camino histórico anterior a 1958, es decir, anterior a la sanción de la Ley

are of wide public or governmental interest, and which should be authoritatively declared by the final court" (Taft, 1925, p. 2). En similar sentido, ver Breyer (2006, p. 92).

Énfasis en el original. 
$15271 .{ }^{93}$ Esa reducción en la integración de la Corte Suprema se alcanzó recién en octubre de 2014, luego del fallecimiento de los jueces Carmen Argibay y Enrique Petracchi. ¿Hubo alguna situación inusual en los últimos años que obligue a improvisar un drástico aumento de jueces de la Corte para poder dividirla en salas a pesar de todos los problemas constitucionales y de orden práctico que señalé? Es evidente que no. Si se quiere atacar de raíz el problema del innegable descontrol de casos que tiene la Corte desde hace varios años, no hay que aumentar la cantidad de jueces, sino disminuir su actividad. En este punto, Frankfurter (1939) tiene razón.

En definitiva, a la luz de nuestros antecedentes históricos y de la composición actual de la Corte Suprema, la idea de dividirla en salas parece un experimento forzado de un sector minoritario que, de forma consciente o no, pretende transformar a uno de los tres poderes del Gobierno federal y alterar su estatus y jerarquía, que es igual a la del presidente y a la del Congreso. Se parece demasiado a un Caballo de Troya que intenta maquillar el verdadero objetivo que se propone alcanzar: justificar, con argumentos más o menos sofisticados, un innecesario aumento de jueces en la Corte Suprema para poder someterla y controlarla. Es un canto de sirenas que tiene un riesgo enorme y demasiado conocido en nuestro país. Al final del camino, no vamos a mejorar la Corte. Al contrario, la convertiremos, como hicimos tantas veces, en un tribunal adicto que, indefectiblemente, traicionará su rol de guardián de la Constitución.

\section{Bibliografía}

Aja Espil, J. A. (1964). Consideraciones sobre el proyecto de reorganización de la Corte Suprema. Jurisprudencia Argentina, Doctrina, 1964-IV, 70-74.

Andruet, A. S. (h) (1996). Crítica filosófica a la teoría del Derecho Comparado. Anuario de Derecho Civil, 49(3), 1133-1146.

Arballo, G. (1 de noviembre de 2014). Sobre la posibilidad de una Corte Nacional dividida en "salas”. Saber Derecho. http://www.saberderecho.com/2014/11/sobre-la-posibilidad-de-una-corte. html.

Ayala Corao, C. M. (1997). La justicia constitucional en Venezuela. Anuario Iberoamericano de Justicia Constitucional, (1), 379-408.

Badeni, G. (2010). Tratado de Derecho Constitucional (3a ed., Tomo III). Buenos Aires: La Ley.

93 Ver discurso de la senadora Fernández de Kirchner (Diario de Sesiones..., 2006, p. 38, sesión ordinaria del 22 de noviembre de 2006). 
Barcesat, sobre la reforma judicial: "Nada de lo que está en este proyecto lesiona la constitución nacional". (18 de agosto de 2020). Ámbito. https://www.ambito.com/politica/justicia/barcesat-la-reforma-judicial-nada-lo-que-esta-este-proyecto-lesiona-la-constitucion-nacional-n5125682.

Berçaitz, M. A. (1988). La Corte Suprema de Justicia de la Nación. El Derecho, 126-859.

Bianchi, A. B. (1988). La Corte dividida en salas (¿Una Corte o muchas Cortes?). El Derecho, 126-971.

Bidart Campos, G. J. (1967) El derecho constitucional del poder (Tomo II). Buenos Aires: Ediar.

Bielsa, R. (1958). Número de jueces de la Corte Suprema de Justicia. La Ley, 92-319.

Brennan, W. Jr. (1960). State Court Decisions and the Supreme Court. Pennsylvania Bar Association Quarterly, 31(4), pp. 393-407.

Breyer, S. G. (2006). Reflections on the Role of Appellate Courts: A View from the Supreme Court. Journal of Appellate Practice and Process, 8(1), 91-100.

Collantes de Terán de la Hera, M. J. (2006). La Administración de Justicia en la época constitucional (1812-1936). Cuenca: Alfonsípolis.

Constantinesco, L. J. (1971). Rechtsvergleichung (Tomo I). Saarbrücken: Carl Heymanns Verlag.

Davies, R. E. (2006). A Certain Mongrel Court: Congress's Past Power and Present Potential to Reinforce the Supreme Court. Minnesota Law Review, 90(3), 678-726.

Doerfler, R. D. y Moyn, S. (2021). Democratizing the Supreme Court. California Law Review, 109, 1-71.

Eduardo Freiler: "Extender la Corte Suprema a un gran número de jueces divididos por salas especializadas”. (2 de agosto de 2020). Radio Gráfica. https://radiografica.org. ar/2020/08/02/eduardo-freiler-extender-la-corte-suprema-a-un-gran-numero-de-jueces-divididos-por-salas-especializadas/.

Ekmekdjian, M. A. (2016). Tratado de Derecho Constitucional ( $3^{\mathrm{a}}$ ed., Tomo V, actualizada por P. Manili). Buenos Aires: Abeledo Perrot.

Frankfurter, F. (1939). The Supreme Court of the United States. En Mac Leish, A. y Prichard, E. F., (Eds.), Law and Politics. Occasional Papers of Felix Frankfurter. 1913-1938. Nueva York: Harcourt, Brace \& Co.

Frankfurter, F. y Landis, J. M. (1928). The Supreme Court under the Judiciary Act of 1925. Harvard Law Review, 42(1), 1-29.

Frontera, C. G. (1995). La reforma constitucional como objetivo de la Revolución de 1930. Revista de Historia del Derecho, (23), 95-154.

García-Mansilla, M. J. y Ramírez Calvo, R. (2006). Las Fuentes de la Constitución Nacional. Buenos Aires: LexisNexis.

García-Mansilla, M. J. y Ramírez Calvo, R. (2008). La Constitución Nacional y la obsesión antinorteamericana. Salta: Virtudes.

Giménez Bonet, A. B. (1947). La Constitución de 1826. Buenos Aires: Centro de Historia Mitre.

Guthrie, C. y George, T. E. (2008). "The Threes": Re-Imaging Supreme Court Decisionmaking. Vanderbilt Law Review, 61, 1825-1860.

Hart, H M. y Weschler, H. (1953). The Federal Courts and the Federal System. Brooklyn: The Foundation Press, Inc.

Ibarguren, C. (1948). La reforma constitucional. Sus fundamentos y estructura. Buenos Aires: Valerio Abeledo. 
Linares Quintana, S. V. (1987). Tratado de la Ciencia del Derecho Constitucional Argentino y Comparado (Tomo 9). Buenos Aires: Plus Ultra.

Montes de Oca, M. (1896). Lecciones de derecho constitucional (Tomo II). Buenos Aires: Imprenta La Buenos Aires.

Mussolini, B. (1941). El espíritu de la revolución fascista. Buenos Aires: Litterae.

Nogueirá Alcalá, H. (2005). La Justicia y los Tribunales Constitucionales de Indoiberoamérica del Sur. En la alborada del Siglo XXI. Santiago: LexisNexis.

Oyhanarte, M. (h). (2013). La Corte del 60: Poder moderador ante una democracia cercada (1958-1966). En Santiago, A. (h) (Dir.), Historia de la Corte Suprema Argentina (Tomo II). Buenos Aires: Marcial Pons.

Quesada Zapiola, C. (Rec.). (1948). Catálogo de la documentación referente a las relaciones diplomáticas entre Estados Unidos de América y la República Argentina. 1810-1830. Archivo General de la Nación. Buenos Aires: Guillermo Kraft Ltda.

Ramella, P. A. (2008). Tribunales constitucionales. En Linares Quintana, S. V., Fayt, C. S., Badeni, G., Bianchi, A. B., Maraniello, P. A. y Carnota, W. F. (Dirs.), Derecho Constitucional. Doctrinas Esenciales (Tomo I). Buenos Aires: La Ley.

Ramírez Calvo, R. (2010). El recurso extraordinario por arbitrariedad de sentencia. Una evaluación en perspectiva comparativa. En Manili, P. L., Tratado de Derecho Procesal Constitucional (Tomo III). Buenos Aires: La Ley.

Ratti, F. S. y Díaz Solimine, I. (5 de noviembre de 2020). ¿Conviene dividir la Corte en salas? Problemas en torno al precedente. El Dial. Suplemento de Derecho Constitucional. https:// www.eldial.com/nuevo/suple-constitucional.asp.

Ravignani, E. (1927). Historia constitucional de la República Argentina (Tomo III). Buenos Aires: Casa Jacobo Peuser.

Ravignani, E. (1937). Asambleas Constituyentes Argentinas (Tomo III). Buenos Aires: Casa Jacobo Peuser.

Robinson, N. (2013). Structure Matters: The Impact of Court Structure on the Indian and the U.S. Supreme Courts. The American Journal of Comparative Law, 61, 173-208.

Romero, C. E. (1976). Derecho Constitucional (Realidad política y ordenamiento jurídico) (Tomo II). Buenos Aires: Víctor P. de Zavalía.

Rosales Cuello, R. (1993). Un tribunal necesario (factible creación de un tribunal para el control de las sentencias viciadas de arbitrariedad). La Ley, 1993-E, 994.

Rosatti, H. (2017). Tratado de Derecho Constitucional (2a ed., Tomo II). Buenos Aires: Rubinzal Culzoni.

Rosatti, H. (2018). La Corte Suprema. Entre Escila y Caribdis. La Ley, 2018-B, 986.

Sáenz Carbonell, J. F. y Masís Pinto, M. (2006). Historia de la Corte Suprema de Justicia de Costa Rica. San José: Editorama.

Sagüés, N. P. (2017). Derecho constitucional (Tomo 2). Buenos Aires: Astrea.

Sampay, A. E. (1949). La Reforma Constitucional. La Plata: Biblioteca Laboremus.

Scalia, A. y Garner, B. A. (2012). Reading Law: The Interpretation of Legal Texts. St. Paul: Thomson/West.

Seco Villalba, J. A. (1943). Fuentes de la Constitución Argentina. Buenos Aires: Depalma.

Segovia, L. (1914). Historia de las leyes. Acto legislativo número 3 de 1910. Cartagena: Imprenta Nacional. 
Sehinkman, D. (1 de noviembre de 2014). Políticos en el diván / Primera sesión. León Arslanian: "La Corte se podría ampliar a nueve miembros, me parece". La Nación. https://www.lanacion. com.ar/politica/sin-titulo-nid1740512/.

Sevilla Andrés, D. (1969). Constituciones y otras leyes y proyectos políticos de España (Tomo I). Madrid: Editora Nacional.

Spota, A. A. (1995). El Consejo de la Magistratura en la Constitución Nacional. La Ley, 1995. $D, 1366$.

Spota, A. A. (2001). Recurso Extraordinario. Buenos Aires: La Ley.

Sternberg, J. (2008). Deciding Not to Decide: The Judiciary Act of 1925 and the Discretionary Court. Journal of Supreme Court History, 33, 1-16.

Taft, W. H. (1925). The Jurisdiction of the Supreme Court under the Act of February 13, 1925. Yale Law Journal, 35, 1-12.

Valenzuela Beltrán, R. J. (1967). El Poder Judicial de la Constitución de 1826. Lecciones y Ensayos, (34), 45-64.

Whilloughby, W. W. (1929). The Constitutional Law of the United States (Tomos I y III). Nueva York: Baker, Voorhis \& Co.

Wurman, I. (2017). A Debt Against the Living. An Introduction to Originalism. Nueva York: Cambridge University Press.

Zaffaroni propone una Corte Suprema “de 15 jueces, dividida en 5 salas especializadas”. (17 de julio de 2020). IProfesional. https://www.iprofesional.com/politica/319804-zaffaroni-propone-una-corte-suprema-de-15-jueces-en-5-salas.

Zavalía, C. (1941). Derecho Federal (3a ed., Tomo I). Buenos Aires: Cía. Argentina de Editores.

\section{Fuentes}

Constitución de la República Argentina sancionada por el Congreso General Constituyente el 24 de diciembre de 1826 y el Manifiesto que se remite a los pueblos para su aceptación (1826). Buenos Aires: Imprenta del Estado.

Congreso Nacional. Actas de las sesiones de la Cámara de Diputados. 1857-1858 (1891). Buenos Aires: Cía. Sud-Americana de Billetes de Banco.

Congressional Record. Proceedings and Debates of the First Session of the Seventy-Fifth Congress. Vol. 81 - Part 3 (1937). Washington, DC: United States Government Printing Office.

Debates in the Congress of the United States, On the Bill for Repealing the Law "For the More Convenient Organization of the Court Of the United States;" During the First Session of the Seventh Congress, And a List of the Yeas and Nays on that Interesting Subject (1802). Albany: Whiting, Leavenworth \& Whiting.

Diario de Sesiones de la Cámara de Diputados de la Nación, 5a sesión de prórroga, 29/11/1901. Diario de Sesiones de la Cámara de Senadores de la Nación, 23a sesión de prórroga, 28/12/1901. Diario de Sesiones de la Cámara de Diputados de la Nación, 86a reunión, 12/01/1960.

Diario de Sesiones de la Cámara de Diputados de la Nación, 87a reunión, 13/01/1960.

Diario de Sesiones de la Cámara de Senadores de la Nación, 81ª reunión, 3/02/1960.

Diario de Sesiones de la Cámara de Senadores de la Nación, Boletín N 416, 28a reunión, $25^{a}$ sesión ordinaria, 22/11/2006.

Diarios de Sesiones de la Cámara de Senadores, Número 43, 40ª sesión ordinaria, 18/08/1857. 
La obra de la Revolución. Reseña sintética de la labor desarrollada. 6 de septiembre de 19301931 (s.f.). Buenos Aires: Talleres Gráficos Linari.

Manifiesto del Excmo. Señor Presidente del Gobierno Provisional de la Nación, Teniente General don José F. Uriburu, del 1 de octubre de 1930. En Documentos Iniciales de la Revolución, Buenos Aires (1930).

Organización y Competencia de la Corte Suprema de Justicia. Consideración por el Honorable Senado del mensaje y proyecto de ley del Poder Ejecutivo en las sesiones de los días 13/14 y 14/15 de agosto de 1964 (1964). Buenos Aires: Imprenta del Congreso de la Nación.

Proyecto de ley presentado por los senadores Marcelo Fuentes, Virginia M. García, Silvina García Larraburu, Juan Irrazábal, María Labado, Mirtha M. T. Luna, Anabel Fernández Sagasti, María Pilatti Vergara, Inés I. Blas, Ruperto Godoy, Ana C. Almirón, Hilda C. Aguirre de Soria, María de los Ángeles Sacnun y Nancy González en 2016. https://www.senado.gob. ar/parlamentario/comisiones/verExp/1967.16/S/PL.

Proyecto de ley presentado por los senadores Norma Durango, Juan Manuel Abal Medina, Marina Riofrio, Sigrid Kunath, María Graciela de la Rosa y Beatriz G. Mirkin de Alperovich, en 2016. https://www.senado.gob.ar/parlamentario/comisiones/verExp/2039.16/S/PL.

Texto original de la Constitución de México de 1917 y de las reformas publicadas en el Diario Oficial de la Federación del 5 de febrero de 1917 al 1 de junio de 2009. https://archivos. juridicas.unam.mx/www/bjv/libros/6/2802/8.pdf.

\section{Legislación citada}

Decreto 635/2020, BO 30/07/2020. https://www.boletinoficial.gob.ar/detalleAviso/prime$\mathrm{ra} / 232757 / 20200730$.

Ley 15271, BO 9/02/1960. http://servicios.infoleg.gob.ar/infolegInternet/verNormado?id=114501.

\section{Jurisprudencia citada}

\section{Corte Suprema de Justicia de la Nación}

D. Eduardo Sojo, por recurso de Habeas Corpus, contra una resolución de la H. Cámara de Diputados de la Nación, Fallos: 32:120 (1887).

Aumento del número de jueces de la Corte Suprema, Fallos: 241:112 (1958).

S.A. Alejandro Bianchi y Cía. v. Nación Argentina, Fallos: 248:398 (1960).

Julio Goldberg v. Orbe Films, Fallos: 248:442 (1960).

Consulta de la Comisión de Interior y Justicia del H. Senado de la Nación, Fallos: 259:214 (1964).

Santiago Cardoso v. Ernestina Magna Sánchez de Llano y otros, Fallos: 262:300 (1965).

Corte Suprema de Justicia de la Nación. Pronunciamiento sobre proyecto de ley modificatorio de la composición del Tribunal, Fallos: 312:1513 (1989).

Mabel Itzcovich v. ANSES, Fallos: 328:566 (2005).

Matias Eugenio Casal y otro, Fallos: 328:3399 (2005).

Rizzo, Fallos: 336:760 (2013). 